\title{
The comovement of option listed stocks
}

\author{
Sam Agyei-Ampomah ${ }^{\mathrm{a}, *}$, Khelifa Mazouz ${ }^{\mathrm{b}}$ \\ ${ }^{a}$ School of Management, University of Surrey, Guildford, UK, GU2 7XH \\ ${ }^{b}$ Bradford University School of Management, Emm Lane, Bradford, UK, BD9 4JL
}

This version: 3 January 2011

\begin{abstract}
This study examines the changes in return comovement around the listing and delisting of stock option contracts. We show that newly option listed stocks experience an increase in comovement with a portfolio of option listed stocks and a decrease in comovement with the portfolio of non-optioned stocks. Similarly, stocks that undergo option delisting exhibit a decrease in comovement with option listed stocks and an increase in comovement with non-optioned stocks. We verify the reliability of our findings in several ways. A matched sample analysis suggests that our results are not driven by factors other than option listing and we find similar results using a calendar-time approach. Further analysis reveals that commonalities in option trading may induce the comovement in the option listed stocks. Overall, our evidence is consistent with the predictions of the category or habitat view of comovement.
\end{abstract}

JEL Classification: G12

Keywords: Comovement; Equity option listing; Beta

* Corresponding author. Tel.: +44 148368 3094; fax: +44 1483683094

Email addresses: s.agyei-ampomah@surrey.ac.uk (S. Agyei-Ampomah), k.mazouz@bradford.ac.uk (K. Mazouz)

\section{Acknowledgements}

The comments provided by colleagues at Bradford University, Sheffield University and the University of Surrey, in particular Mark Freeman, Andrew Mason and Shuxing Yin on earlier versions of the manuscript, are gratefully appreciated. We thank the participants of the 2010 Multinational Finance Society (Barcelona) for valuable comments. The paper has also benefited immensely from the comments of an anonymous referee and the editor. 


\section{Introduction}

The analysis of the impact of equity derivative contracts on the market quality of the underlying stocks has garnered growing interest among academics, practitioners and regulatory bodies. The main focus of existing studies has been the effects of listing derivative contracts on the price, volatility and various aspects of the market quality of the underlying stocks. ${ }^{1}$ In this study, we take a completely different approach. Our purpose is to examine the return comovement around the listing and the delisting of equity option contracts.

Several studies show strong common factors among different types of stocks. Zhen (2007) finds positive comovement in the prices of small cap stocks, large cap stocks, value stocks and growth stocks. Bodurtha et al. (1995) show that market sentiments explain part of the closed-end country funds premiums and discounts. Pirinsky and Wang (2006) report strong comovement in the prices of stocks of firms headquartered in the same geographic location. Kumar and Lee (2006) find strong comovement amongst stocks that are held and traded by retail investors. Similar evidence is reported by Pirinsky and Wang (2004) on the stocks held and traded by institutional investors. Vijh (1994) and Barberis et al. (2005) show that stocks added to S\&P 500 comove more with the existing constituents of the index. Similar evidence is reported by Coakley and Kougoulis (2005) and Greenwood (2008) for the FTSE 100 and the Nikkei 225, respectively. Finally, Green and Hwang (2009) find strong comovement amongst similarly priced stocks. Specifically, they find that stocks that undergo stock splits covary more with low-priced stocks and less with high-priced stocks.

These papers show that the comovement of stock returns cannot be fully explained by their common fundamentals. Different papers offer explanations that are unique to their comovement evidence. However, Barberis et al. (2005) propose two main theories that seem

\footnotetext{
${ }^{1}$ See, for example, Froewiss (1978), Figlewski (1981), Edwards (1988), Harris (1989), Simpson and Ireland (1985), Sahlstrom (2001), Mazouz (2004), Mayhew and Mihov (2004) and Ni et al. (2005) for studies on the US market, and Hamill et al. (2002) and Faff and Hillier (2005) for studies on equity option listings in the UK.
} 
to fit well with all aspects of the comovement literature. One of these theories is based on frictionless economies (fundamentals-based theory) and the other is based on economies with frictions (friction-based theory). The fundamentals-based theory relates any changes in comovement to the contemporaneous changes in cash flows and/or discount rates. However, the friction-based theory suggests that comovement in prices reflects the characteristics of economies with frictions or irrational behaviour such as investor sentiments and limits to arbitrage.

Barberis et al. (2005) distinguish between three different views of the friction-based theory. The first is the category view of Barberis and Shleifer (2003), which suggests that investors group assets into categories, such as small cap stocks, industry stocks, index stocks, before allocating their funds. The second is the habitat view, which predicts that many investors trade only in a subset of securities. This view expects strong comovement among securities that are held and traded by a specific subset of investors, such as individual investors or institutional investors. The information diffusion view is the third friction-based explanation of comovement in stock returns. This view is based on the speed of price adjustment to information. It predicts commonalities in the returns of stocks that incorporate information at similar rates.

In this study, we examine a new source of return comovement related to the introduction of stock option contracts. The inception of stock option contracts allows us to test whether investors distinguish between optioned and non-optioned stocks when making investment decisions. London International Financial Futures and Options Exchange (LIFFE) claims that listing an option contract on an underlying stock is determined merely by the stock's market capitalisation, current volatility and popularity among investors. Since the listing requirements are public knowledge, option listing should not convey any new information on the firm's fundamentals. Thus, the fundamentals-based theory does not 
predict any change in the correlation of a newly option listed stock's return with the returns of other option listed stocks.

The friction-based theory predicts that a newly option listed stock will covary more with other option listed stocks. The category view suggests that investors group assets into categories or investment styles and then allocate funds at the category level rather than across individual securities. If investors view option listed stocks as a style of investing, they will trade when stocks become members of the option listed stocks family rather than on the basis of changes in fundamentals of such stocks. This kind of trading is expected to induce commonality in the stock price movements of option listed stocks even when the cash flows of these particular stocks are largely uncorrelated.

The preferred habitat view also predicts strong correlation among option listed stocks. Investors may choose option listed stocks as a preferred habitat for several reasons. ${ }^{2}$ If this is the case, the market price of the option listed stocks will comove with investors' demand shifts even when the fundamentals of such stocks remain unchanged. As investors' risk aversion, sentiments and liquidity change, they alter their exposure to the option listed stocks. This demand shift will, in turn, induce commonalities in stock price movements in the option listed stocks. More generally, the habitat view predicts that option listed stocks will comove as they are traded and held by a subset of investors with similar sentiments, risk aversion and other characteristics.

Finally, the information diffusion view also predicts positive correlation among option listed stocks. Due to their inherent leverage and lower transaction costs, the introduction of option contracts may attract new investors to both the stock and the option market. The effect of option listing on the speed of price adjustment to information will

\footnotetext{
${ }^{2}$ The hedging and speculating opportunities associated with options may make optioned stocks a preferred habitat of some investors. Lakonishok et al. (2006), for example, show that covered calls are the most popular strategies in the options markets. If the covered call holders share common sentiments, their demand for option listed stocks may cause these stocks to comove.
} 
depend on the informativeness of the newly attracted investors (see, for example, Figlewski, 1987). Furthermore, the opportunity to use options to construct portfolios which effectively circumvent restrictions imposed on selling short may increase the attractiveness of the option market to the informed investors. Thus, option listing may increase the speed at which prices are reflected in the stock price by enabling informed investors to trade quickly and efficiently on their private information. Roll et al. (2010) show that at least part of the option trading around earnings announcement is informed. However, Gorton and Pennacchi (1993) claim that derivative markets increase the attractiveness of the stock market to noisy investors. This is because options offer noisy investors opportunities to hedge their stock market positions at low costs. The increased amount of noise trading in the stock market may, in turn, delay the speed at which new information is incorporated into the stock price. Despite the ambiguities, the above theoretical discussion suggests that option listing is likely to affect the speed of price adjustment to information. ${ }^{3}$ This effect may cause a newly option listed stock to incorporate market-wide news at the same time as other option listed stocks, rather than, say, a day later. Consequently, the information diffusion view expects a stock's return to comove more with the returns of other option listed stocks after option listing.

We measure the shifts in newly option listed stocks' comovement with the index of option listed stocks before and after option listings using a univariate regression analysis similar to Vijh (1994), Barberis et al. (2005) and Green and Hwang (2009). The results of this analysis are consistent with the predictions of the friction-based theory of comovement. Specifically, the correlation of a stock's return with the return of the index of option listed stocks increases significantly after option listing. In the subperiod analysis, the increase in the comovement amongst optioned stocks is only significant in the more recent period. In light of the growing importance of optioned stocks as both a category and a habitat, this latter finding

\footnotetext{
${ }^{3}$ Antonio and Holmes (1995) and Mazouz and Bowe (2006) report evidence that futures listing affect the speed of price adjustment to information.
} 
is especially supportive of the friction-based theory. ${ }^{4}$ Consistent with the friction-based theory, we show that the return of option delisted stocks comove less with optioned stocks and more with the remaining stocks.

For a better distinction between the fundamentals-based and the friction-based theories, we perform a bivariate regression analysis. Specifically, we regress a stock's return on both the return of the index of optioned stocks and the return of the index of non-optioned stocks. To observe the change in the comovement, we estimate the bivariate analysis for both pre- and post-option listing periods. The friction-based view predicts that the comovement of a stock's return with the return of the index of optioned stocks should increase, whilst the correlation between that stock's return and the return of the index of non-optioned stocks should decrease after option listing. However, the fundamentals-based theory does not predict any changes, between pre- and post-option listing periods, in the coefficients on the index of optioned stocks and the index of non-optioned stocks.

The results of the bivariate regressions also support the predictions of the frictionbased theory. Specifically, we show that option listing is generally associated with a significant increase in the coefficient on the index of optioned stocks and a decline in the coefficient on the index of non-optioned stocks. Significant results in the opposite direction are observed following option delisting events. The effect of option listing and delisting is particularly strong at daily and monthly frequencies.

We verify the robustness of our results in many ways. First, we use a control sample methodology to show that the changes in the comovement are not caused by factors other than option listings. Second, we use a calendar time portfolio approach, instead of an event time approach, to deal with the issue of cross-sectional dependences that might occur in our sample. The two approaches produce very similar results. Finally, we apply Dimson’s (1979)

\footnotetext{
${ }^{4}$ If option listing affects the firm's fundamentals, the effect should have not been exclusive to the more recent periods. This evidence is similar to Barberis et al. (2005) in the context of S\&P 500 index revision.
} 
approach to show that the change in the comovement of optioned stocks is better explained by the category and habitat views than the information diffusion view.

The final part of this study tests whether the comovement of the option listed stocks is driven by the trading activity in options or underlying stocks. After controlling for changes in fundamentals, we show comovement is positively related to call option volume, but not related to the put option volume or stock volume. We conclude that commonality in option trading may serve to induce a commonality in stock price movements of option listed stocks.

The rest of the paper is organised as follows. Section 2 describes our data set. Section 3 presents our empirical procedures and discusses our findings. Section 4 concludes the paper.

\section{Data}

The data on dates of option listing and delisting is collected from the LIFFE and includes all stocks with listed and/or delisted options between 1978 and 2007. There were a total of 185 stock option listings during this period. Table 1 shows the number of new stock option listings in each year between 1978 and 2007. The first stock option listing in the UK occurred in 1978 and there have been only 35 stock option listings as at the end of December 1985. In our comovement analysis, we construct an index of option listed stocks. To obtain a reliable index return measure, we require a reasonable number of stocks. Due to the limited number of option listing events in earlier periods, we choose to focus our comovement analysis on stock options listed/delisted between January 1986 and December 2007.

As shown in Table 1, there were no stock option listings in 2007. Of the remaining sample stocks, we also require a minimum of 12 months of daily return data before and after listing/delisting to be included in the comovement analysis. For the weekly and monthly return analysis, we require 24 months and 36 months returns data, respectively, before and after the date of option listing/delisting. A number of sample stocks were dropped due to 
insufficient data. For example, most of the post privatisation and demutualised stocks did not have sufficient pre-listing return data. Hence the final sample of option listed stocks used in our comovement analysis is 99 firms for daily and weekly return analysis and 88 firms for the monthly return analysis. Although 98 stock options were delisted during the period 1986 2007, most of the delistings were as a result of bankruptcy, takeovers or mergers for which the required post-delisting returns data were not available. Consequently, the delisting sample contains only 20 stocks for daily and weekly return analysis and 17 stocks for the monthly return analysis. Only 40 of the option listed stocks have option volume data available immediately after option listing. ${ }^{5}$ Data on option volume, stock volume, stock returns and other stock characteristics were obtained from Datastream and covers the relevant period up to December 2008.

\section{[Insert Table 1 about here]}

\section{Tests and results}

The friction-based theory predicts that a stock's return will comove more (less) with the return of the portfolio of optioned stocks following the listing (delisting) of an option contract on that stock. To test this hypothesis, for each stock we estimate the following regression separately before and after the event (i.e. option listing or delisting):

$$
R_{i, t}=\alpha_{i}+\beta_{i} R_{O P T, i, t}+s_{i, t}
$$

\footnotetext{
${ }^{5}$ Trading volume data on stock options were not available until February 1991.
} 
where $\mathbf{R}_{1, t}$ is the return of an event stock $i$ at time $t, \mathbf{R}_{\text {DPT } \mathbf{u t}}$ is the value-weighted return of all optioned stocks at time $t$ but excluding the event stock, and $\varepsilon_{i, t}$ is the error term. Specifically, $\mathbb{R}_{\hbar, O P T, t}$ is calculated as:

$A_{O P T, t, t}=\frac{\Sigma_{1+1} M V_{l, t-1} R_{j, t}}{\Sigma_{1 \pm 1} M V_{g,-1}}$

We exclude the contribution of the event stock from the return of the optioned portfolio, to avoid spurious regression effects. We estimate the above regression at daily, weekly and monthly frequencies. For the daily frequency, we estimate the pre-event regression over the 12-month period ending 1-month prior to the event and the post-event regression is run over the 12-month period beginning 1-month after the event. For the weekly and monthly frequencies, we extend the estimation period of both pre- and post-event regressions to 24 months and 36 months, respectively. ${ }^{6}$

\section{[Insert Tables 2 and 3 about here]}

The cross-sectional distribution of the changes in the slope coefficient, $\Delta \beta$, and the changes in the $\mathrm{R}^{2}, \Delta \mathrm{R}^{2}$, are presented in Table 2. The table reports the number of stocks in the sample $(\mathrm{N})$, mean, standard deviation (StDev), minimum, first quartile (Q1), median, third quartile (Q3), maximum and the proportion of positive changes $(\%>0)$. The results show that for a greater proportion of the sample, the change in the univariate slope coefficient, $\Delta \beta$, is positive. Specifically, $\Delta \beta$ is positive in $63.6 \%, 58.6 \%$ and $56.6 \%$ of the cases at daily, weekly and monthly frequencies, respectively. The change in the $\mathrm{R}^{2}, \Delta \mathrm{R}^{\mathbf{2}}$, is also positive in

\footnotetext{
${ }^{6}$ Note that monthly returns are calculated over periods of one calendar month beginning at the option listing date. For example, for a stock option listed on $22^{\text {nd }}$ of a given month, monthly returns are calculated over the period from the $22^{\text {nd }}$ of one month to the $21^{\text {st }}$ of the subsequent month.
} 
$60.6 \%, 58.6 \%$ and $48.9 \%$ of the cases at daily, weekly and monthly frequencies, respectively. In Table 3, we report the results of the tests whether the cross-sectional average change in the slope coefficient, $\overline{\Delta \beta}$, and the cross-sectional average of the change in the $\mathrm{R}^{2}, \overline{\Delta \mathbb{R}^{2}}$, of Eq.(1) are significantly greater than zero. The reported t-values are based on standard errors clustered by month to adjust for any possible dependence across the sample. ${ }^{7}$ We test the null hypothesis of no change in comovement against the alternative of a positive (negative) change for listing (delisting) events. Thus, similar to Barberis et al. (2005) we report statistical significance based on a one-sided test. The one-sided test is appropriate in this study because the predictions of the friction-based view of comovement suggest that the change in comovement cannot be negative (positive) for listing (delisting) events. Consequently, a negative (positive) change in comovement for listing (delisting) events can be attributed to chance and an acceptance of the null hypothesis of no change in comovement. $^{8}$

The results show that $\overline{\Delta \beta}$ is generally positive and significant after option listing. Over the full sample period, the coefficient $\beta_{i}$ in Eq.(1) increases significantly after option listing by $0.1082,0.1240$ and 0.0847 for daily, weekly and monthly returns, respectively. The $\mathrm{R}^{2}$ increases by $2.47 \%, 4.14 \%$ and $1.7 \%$ at daily, weekly and monthly frequencies, respectively. In comparison, Barberis et al. (2005) show that the daily, weekly and monthly betas of the stocks added to the S\&P 500 increase significantly by $0.151,0.110$ and 0.042 , respectively, after additions. Similarly, Green and Hwang (2009) find that the daily and weekly price-index coefficient increases significantly by 0.219 and 0.191 , respectively, following stock splits. The distribution of $\Delta \beta$ and $\Delta R^{2}$, as presented in Table 2, also shows that a greater proportion of the optioned stocks experience an increase in the post-listing

\footnotetext{
${ }^{7}$ All reported t-values, apart from those associated with the test of proportions, are based on standard errors clustered by month.

${ }^{8}$ Our conclusions are generally unaffected even if a two-sided test is used.
} 
coefficient $\beta_{i}$ and $R^{2}$. This suggests that our results are unlikely to be driven by extreme values.

All things being equal, an increase in return volatility following option listing can also lead to an increase in the coefficient $\beta_{i}$. The observed increase in the coefficient $\beta_{i}$ following stock option listing is therefore consistent with the view that return volatility increases following option listing. Several studies, including Faff and Hillier (2005), find an increase in return volatility following stock option listings. The increase in return volatility is generally attributed to several factors, including the migration of informed traders from stock markets to the option markets (see, for example, Faff and Hillier, 2005). However, as we find a significant increase in the regression $\mathrm{R}^{2}$, the increase in the coefficient $\beta_{1}$ could also be attributed to the increase in return correlation with the return of the portfolio of optioned stocks.

We examine the issue of changes in return volatility as an explanation for the shifts in the coefficient $\beta_{i}$. For each stock, we calculated the natural log of the ratio of the post-listing return variance to the pre-listing return variance. If return volatility increases after option listing, we would expect the cross-sectional average of the log ratio to be significantly greater than zero. We did not find any significant differences in the return volatility before and after option listing across all data frequencies and subperiods. For the full sample period, the mean $\log$ ratio of the return variances are $0.0076(\mathrm{t}$-statistic $=0.1058)$ for daily returns, $0.0289(\mathrm{t}-$ statistic $=0.3618)$ for weekly returns and 0.1030 (t-statistic $=1.0637)$ for monthly returns. Using similar log-ratio tests, we then examined the changes in return correlations with the portfolio of optioned stocks following option listing. For each stock, the log correlation ratio is calculated as the natural log of the post-listing correlation divided by the pre-listing correlation. The average $\log$ correlation ratios are $0.0650(\mathrm{t}$-statistic $=1.7813)$ for daily returns, 0.0561 (t-statistic $=1.3744)$ for weekly returns and 0.0516 (t-statistic $=1.2761)$ for 
monthly returns. Hence, the shifts in the coefficient $\beta_{i}$ cannot be attributed to increases in return volatility. It is also interesting to note that the increase in return volatility observed in Faff and Hillier (2005) might be transitory as they observe the change in return volatility over a 10 day window.

Our subperiod analysis shows that the increase in $\beta_{i}$ and the $\mathrm{R}^{2}$ after option listing is much larger in the more recent period. ${ }^{9}$ During the period 1986-1998, the average change in beta, $\overline{\Delta Q}$, is negative and statistically insignificant for all three horizons (daily, weekly and monthly). The average change in $\mathrm{R}^{2}, \overline{\Delta \mathrm{R}^{2}}$, is also small and statistically significant only for the weekly data. However, the later bivariate analysis yields consistent results across the two subperiods. Over the more recent period, 1999 to 2007, $\overline{\Delta \beta}$ and $\overline{\Delta \mathrm{R}^{\mathbf{2}}}$ are shown to be positive, larger and strongly significant at all frequencies. Our results are thus consistent with the findings of Barberis et al. (2005) that the increase in the S\&P betas is larger in more recent periods. Similar evidence is also reported by Green and Hwang (2009) in the context of stock splits. Given the growing importance of option listed stocks both as a category and a habitat, the evidence that the effect of option listing on the comovement of the underlying stocks is only present in more recent periods is especially supportive to the friction-based views. $^{10}$

The friction-based views also predict that a stock's return will comove less with the return of the index of optioned stocks after option delisting. To test this prediction, we estimate Eq.(1) around option delisting periods. The results are also reported in Table 2. At the daily frequency, we observe a decline in the comovement between a stock's return and

\footnotetext{
${ }^{9}$ Due to the paucity of option listing events in the earlier years, we deliberately choose subperiods of unequal length. Despite the difference in the lengths of the sub-periods 1986-1998 and 1999-2007, the two sub-periods contain almost the same number of option listing events. We repeat our analysis over the periods 1986-1996 and 1997-2007 and our conclusions remain unchanged. More details on these results are available upon request. ${ }^{10}$ This argument is also used by Barberis et al.'s (2005) study on the effect of index revisions on the return comovement of the underlying stocks.
} 
the return of the index of optioned stocks by -0.0413 after option delisting. However, the change in $\beta_{i}$ is not significantly different from zero. The average $\overline{\Delta \beta}$ and $\overline{\Delta \mathbf{R}^{2}}$ associated with option delisting events are however larger and more significant at the weekly and monthly frequencies. Specifically, the mean $\overline{\Delta S}$ for the option delisting events is -0.1571 for weekly and -0.5298 for monthly returns. These figures are significant at 10 percent and 5 percent levels, respectively. Similarly, $\mathrm{R}^{2}$ declines following option delisting by $-2.14 \%$ and $10.42 \%$, on average, for weekly returns and monthly returns, respectively. Thus, the option delisting evidence is consistent with the predictions of the friction-based theory at least for weekly and monthly frequencies. ${ }^{11}$

\subsection{Bivariate Regressions}

To control for the impact of changes in fundamentals following the option listing or delisting, we estimate a bivariate regression that includes both the return on the index of option listed stocks and the return on index of stocks with no listed options. Our bivariate regression is specified as follows:

$$
R_{i, t}=\alpha_{i}+\beta_{i, O P T} R_{O P T, i, t}+\beta_{t, N O P T} R_{N O P T, t}+\gamma_{i, t}
$$

where $R_{\text {NOPT,t }}$ is the return on the portfolio of all non-optioned stocks at time t, calculated from the return on the FTSE All Share index, the return on the optioned portfolio and their market capitalisations. Specifically, $R_{\text {NOPT }, t}$ is computed as:

$$
R_{N O P T, t}=\frac{M V_{A L L, t-1} R_{A L L, t}-M V_{O R T, t-1} R_{O R T, t}}{M V_{A L L, t-1}-M V_{O P T, t-1}}
$$

\footnotetext{
${ }^{11}$ The results of the delisting sample should be interpreted with caution given the small sample size.
} 
Here $M V_{A L L, t-1}$ is the total market capitalisation of the FTSE All Share index; $M V_{O P T, t-1}$ is the total market capitalisation of all the optioned stocks; $R_{A L L, t}$ is the return on the FTSE All Share index and $R_{O F T, 6}$ is the value-weighted return on the portfolio of all optioned stocks. The parameters $\beta_{1,0 \mathrm{PT}}$ and $\beta_{1 \mathrm{NOPT}}$ in Eq. (2) are the loading factors on the index option listed stocks and the index of non-option listed stocks, respectively, $\Upsilon_{1 t}$ is the error term and the rest of the variables are as previously defined in Eq.(1).

\section{[Insert Fig. 1 about here]}

Fig. 1 shows the standard deviations of the returns of the portfolio of optioned stocks, $\sigma(\mathrm{OPT})$, and the portfolio of non-optioned stocks, $\sigma(\mathrm{NOPT})$, plotted against the left axis and the correlation between the two portfolios, corr(OPT, NOPT), plotted against the right axis, over time. For daily returns, $\sigma(\mathrm{OPT}), \sigma(\mathrm{NOPT})$ and corr(OPT, NOPT) are estimated separately for each year. For weekly (monthly) returns, the standard deviations and correlations are estimated using a two-year (three-year) rolling window which is moved forward in 12-month intervals. Panel A shows results for daily returns, Panel B shows weekly returns whilst Panel C shows monthly returns. The figure reveals several interesting features about the two portfolios. First, although the volatilities of the two portfolios at a given period are largely similar, they vary over time. The sharp spikes in the volatilities in 1987 coincide with the October 1987 crash whilst the spikes at the end of the sample period coincide with recent market events. Second, it is evident that the two portfolios are highly correlated but 
largely stable over time. ${ }^{12}$ These patterns are consistent across all the different return horizons.

The bivariate regressions are estimated at the same return frequencies and estimation windows as the univariate regressions. The friction-based theory predicts that an option listed (delisted) stock will have an increase (decrease) in the loading on the return on the index of optioned stocks but a drop (rise) in the loading on the return on the index of non-optioned stocks, following option listing (delisting).

The distribution of the change in the factor loading on the portfolio of optioned stocks, $\Delta \mathbb{Q}_{i, O P T}$, and corresponding change in the factor loading on the portfolio of nonoptioned stocks, $\Delta \beta_{1 \text { NoPT }}$, are presented in Table 2 . Table 3 reports the cross-sectional average change, across pre- and post-option listing periods, in the factor loadings, $\overline{\triangle \beta_{O P T}}$ and $\overline{\Delta \beta_{\mathrm{NOPT}}}$, and the corresponding test statistics. The results of the bivariate regressions confirm our findings from the univariate analysis. We observe a substantial and significant increase in $\beta_{1, \text { OPT }}$ and a substantial and significant drop in $\beta_{1 \text { NoPT }}$ after option listing at all data frequencies. Over the full sample period, we find that $\beta_{1 . \mathrm{PT}}$ increases by an average of 0.3147, 0.2745 and 0.3626 at daily, weekly and monthly data frequencies whilst $\beta_{1 \text { NoPT }}$ exhibits an average decrease of $0.2518,0.1684$ and 0.3013 , respectively, following option listing. Table 2 also shows that irrespective of the return frequency, more than $60 \%$ of the option listed stocks experience increases in $\beta_{\ell, Q P T}$, and decreases in $\hat{F}_{\text {t,NOPT }}$ after option listing. These proportions are statistically significant and further supports the view that our results for $\overline{\triangle Q_{O P T}}$ and $\overline{\triangle \beta_{N O P T}}$ are not driven by extreme values.

We also show the results of the bivariate regressions across two subperiods. In a qualitative sense, the bivariate analysis yields consistent results across the two subperiods and

\footnotetext{
${ }^{12}$ The high correlation between the optioned and non-optioned portfolio has some implications for the bivariate analysis presented below.
} 
similar to the univariate findings, we find that the increase in $\beta_{1 \mathrm{OPT}}$ after option listing is generally larger in the latest subperiod. Specifically, the daily, weekly and monthly $\overline{\Delta \beta_{\mathrm{OPT}}}$ increase from $0.2685,0.1516$ and 0.1085 in the first sub-period to $0.3581,0.3901$ and 0.5254 in the second sub-period, respectively. The corresponding evidence for the decline in $\beta_{1 \text { NoPT }}$ across the two sub-periods is however mixed. At daily and weekly frequencies, the magnitude of the decline reduces, but increases for the monthly frequency.

Table 3 also reports the results of the comovement of the option delisted stocks. At daily frequencies, we report a significantly positive $\overline{\mathrm{A} / \mathrm{OPT}}$ and a significantly negative $\overline{\Delta \beta_{\mathrm{NGPT}}}$ after option delisting. At weekly and monthly frequencies, $\overline{\Delta \beta_{\mathrm{OPT}}}$ and $\overline{\Delta \beta_{\mathrm{NOPT}}}$ carry the predicted sign, but the figures are not always significant. Specifically, only $\overline{\Delta \beta_{\mathrm{OPT}}}$ is statistically significant for weekly and monthly returns.

Generally, the power of the t-test is much more problematic in small samples than in larger samples. For robustness purposes, we also use the nonparametric Wilcoxon signedrank test. The conclusions from the nonparametric test are similar to those of the t-test. As an example, consider the delisted stocks sample which contains only 20 stocks for daily returns. We find that the median of the changes in $\beta_{i}$ is 0.0022 (Wilcoxon test statistic, $\mathrm{W}=60.0$, pvalue $=0.511)$; the median of the changes in $\mathrm{R}^{2}$ is $-0.0013(\mathrm{~W}=60.0$, $\mathrm{p}$-value $=0.466)$; the median of the changes in $\beta_{i, O P T}$ is $-0.3967(\mathrm{~W}=16.0$, $\mathrm{p}$-value $=0.007)$; and the median of the changes in $\beta_{\text {tiNOFT }}$ is $0.5266(\mathrm{~W}=108.0$, $\mathrm{p}$-value $=0.003)$. Conclusions from the Wilcoxon test are consistent with the parametric t-test shown in Table $3 .^{13}$

Overall, the results of the bivariate regressions support the predictions of the frictionbased views. It should however be noted that the high degree of correlation between the return on the portfolio of optioned stocks and the return on the portfolio of non-optioned

\footnotetext{
${ }^{13}$ More details on the results of the non-parametric tests can be obtained from the authors.
} 
stocks, as shown in Fig.1, raises collinearity problems in the bivariate regressions. This can lead to potentially large standard errors for parameter estimates, parameters with implausible signs and magnitudes and difficulty in identifying the separate effects of the two independent variables in the bivariate regression. However, as argued in Barberis et al. (2005), regardless of the collinearity issues, the sum of the two slope coefficients, $\beta_{1 \mathrm{OPT}}$ and $\beta_{1 \text { NoPT }}$, would be estimated much more accurately than either of the individual coefficients. If the sum of the two slope coefficients, $\beta_{1.0 \mathrm{PT}}$ and $\beta_{1 \mathrm{NoPT}}$, is estimated more accurately in the pre- and postlisting periods, then it follows that the sum of $\Delta \beta_{\hbar, O F T}$ and $\Delta \beta_{1 \text { NoPT }}$ would also be estimated more precisely. We also observe from Fig. 1 that the correlation between the two portfolios is relatively stable over time. Hence, all things being equal, $\Delta \beta_{t, O P T}$ and $\Delta \beta_{1 \text { NoPT }}$ should not be significantly different from zero. It should also be noted that our interest is in the changes of the coefficients in the pre- and post-listing period, rather than the individual coefficients themselves. The significant changes observed in the bivariate analysis are therefore consistent with the friction-based comovement. Barberis et al. (2005) find similar support for the friction-based comovement.

\section{2. $\quad$ Matching firms}

In general, stock option listing is a decision undertaken by option exchanges. However, one obvious characteristic of optioned stocks is that they tend to be much larger in size compared to non-optioned stocks. ${ }^{14}$ If optioned stocks tend to be larger firms and if firms of similar size tend to covary, then our comovement evidence may be driven by the size effect. This may be particularly the case since firms with similar size tend to share other

\footnotetext{
${ }^{14}$ Although Mayhew and Mihov (2004) show that the influence of firm size in stock option listing decisions have been diminishing in the US, Faff and Hillier (2005) find that the size of firms with stock options is large in comparison to other stocks listed on the London Stock Exchange.
} 
fundamental characteristics, such as cash flows. Therefore, changes in firm size can also induce changes in firm fundamentals. To explore the impact of firm size on our results, we repeat all the analysis on a control sample of non-optioned firms. We match each option listed stock with a control firm in the same size decile, but not necessarily in the same industry, at the time of the option listing. ${ }^{15}$ For the delisted option sample, we match each option delisted stock with an optioned stock with similar size. The control firm should not have any option listing, or delisting in the case of control firms for delisted options, within the following three years.

If the earlier results are driven by changes in firm size, then the post-listing changes in the factor loadings across the sample of optioned stocks should be no different from the corresponding changes in the control sample. In this case, we test whether the average change in the post-listing factor loadings of the sample of optioned stocks minus the corresponding changes in the control sample is significantly different from zero. Thus, for the univariate analysis, for each stock in the optioned sample and the matching control sample, we estimate $\beta_{\mathrm{i}}$ and $\mathrm{R}^{2}$ separately for the pre- and post event period. We then calculate the excess change in the optioned sample over the corresponding change in the matching control sample. ${ }^{16}$ By a similar process, we estimate the excess changes in the factor loadings in the bivariate analysis. The results of this analysis are presented in Table 4.

\section{[Insert Table 4 about here]}

\footnotetext{
${ }^{15}$ Attempts were made to match according to industry and firm size but in many cases we could not find a suitable control firm from the same industry and size decile. Although stock option listing may be common for some industries and in that case matching all optioned stocks by industry and firm size is preferred, we have to sacrifice industry effect for size where a suitable industry and size match is not available.
}

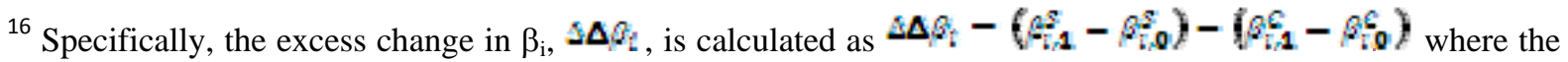
superscripts $S$ and $C$ denote estimates for the optioned sample and matching control sample respectively; and subscripts 0 and 1 denote estimates for the pre- and post-event period. We calculate the excess change in $\mathrm{R}^{2}$, and the excess changes in the factor loadings in the bivariate analysis by a similar process. 
In Table 4, we report the cross-sectional average of the excess change in the slope coefficient $\beta_{i}, \overline{\Delta \Delta \&}$, the cross-sectional average of the excess change in adjusted $R^{2}, \overline{\Delta \Delta r^{2}}$,

the cross-sectional average of the excess change in the factor loading $\beta_{\ell, Q P T}, \overline{\Delta \Delta \beta_{O P T}}$, and

the cross-sectional average of the excess change $\beta_{t, N O P T}, \overline{\Delta \Delta \beta_{X O P T}}$. We find that over the full sample period, $\overline{\Delta \Delta \beta}$ is not significantly different from zero, regardless of the return frequency, suggesting that the post-listing increase in the coefficient $\beta_{i}$ among the optioned stocks is not significantly different from the corresponding increase in the control sample. However, in the subperiod analysis, we observe statistically significant results in the second and most recent subperiod. In Table 3, we report much stronger results across all data frequencies in the second subperiod and this does not appear to have diminished after the matching exercise. Table 4 shows that in the second subperiod, the post-listing $\beta_{i}$ for the optioned sample increases on average by 0.1975 for daily returns, 0.1519 for weekly returns and 0.1874 for monthly returns more than the corresponding increase in the post-listing $\beta_{i}$ for the matched sample. In addition, the post-listing adjusted $R^{2}$ for the optioned sample increases on average by $0.7 \%$ percentage points for daily returns, 4.13 percentage points for weekly returns and 0.87 percentage points for monthly returns more than the corresponding increase for the matched sample, but the difference is statistically significant only for weekly returns.

For the bivariate analysis, the post-listing increase (decrease) in the factor loading $\beta_{t, O F T}$ ( $f_{\text {t,NOPT }}$ ) for the optioned sample, increased (decreased) more than the corresponding 
increase (decrease) in the matched sample. For the full sample period, the average excess increase (decrease) in the factor loadings, $\overline{\Delta \Delta \beta_{\text {OFF }}}\left(\overline{\Delta \Delta \hat{Q}_{\text {NOFF }}}\right)$, are $0.3292(-0.4102)$ for daily returns, $0.2109(-0.2620)$ for weekly returns and $0.1925(-0.1436)$ for monthly returns. These values are strongly statistically significant. The magnitude of these values also suggests that whilst the post-listing factor loadings $\beta_{\hbar, Q P T}$ ( $\beta_{\hbar, E F}$ ) increase (decrease) for the optioned stocks, they tend to decrease (increase) for the matched sample. Thus, whilst optioned stocks exhibit more comovement with the portfolio of optioned stocks and less with the portfolio of non-optioned stocks, the matched sample exhibit more comovement with the non-optioned portfolio and less with the optioned portfolio. To be precise, the matched sample analysis shows that the post-listing comovement of the optioned stocks observed earlier is unlikely to be driven by the changes in the fundamentals of the optioned stocks.

\subsection{Calendar time tests}

We also consider a calendar time portfolio approach to deal with the cross-sectional dependencies that might occur in our sample. We construct two calendar time portfolios, a pre-event portfolio and a post-event portfolio over the period 1986 - 2007. For the pre-event portfolio, each option listed (delisted) stock is added to the portfolio $N$ months before the month of listing (delisting) until the month of listing (delisting). Similarly, for the post-event portfolio, an option listed (delisted) stock is added to the portfolio in the month following option listing (delisting) for $N$ months. Here $N$ equals 12, 24 and 36 in the cases of daily, weekly and monthly frequencies, respectively. The portfolio return at time $t$ is calculated as the equally weighted average return of all stocks in the portfolio. Given the uneven distribution of option listing and delisting over time, there were times (days, weeks, months) where the calendar-time portfolio contained only one stock. We therefore require that, for 
inclusion in the calendar-time analysis, the portfolio at time t should contain at least two stocks.

For each event (listing or delisting), the univariate models

$A_{\text {pret }}=\alpha_{p r e}+\beta_{p r q} R_{O F T, t}+s_{p r e, t}$

and

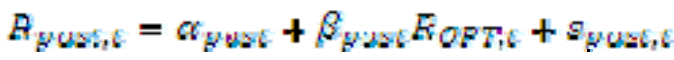

and the bivariate models

$R_{p r e, t}=\alpha_{p r e}+\beta_{p r e, O P T} R_{O P T, t}+\beta_{p r e, N O P T} R_{N O P T, t}+\gamma_{p r e, t}$

and

$R_{\text {post }, t}=\alpha_{\text {past }}+\beta_{\text {past }, O P T} R_{Q P T, t}+\beta_{\text {past }, N O P T} R_{N O P T, t}+\gamma_{\text {past }, t}$

are separately estimated. $\mathrm{R}_{\mathrm{OPT}}$ is the value-weighted returns on the portfolio of stocks with listed options. $\mathrm{R}_{\mathrm{NOPT}}$ is the value-weighted returns on the portfolio of stocks with no listed options. If a shift in comovement occurs following option listing, we would expect

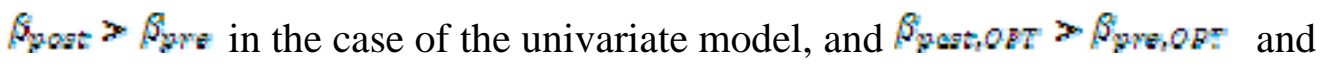

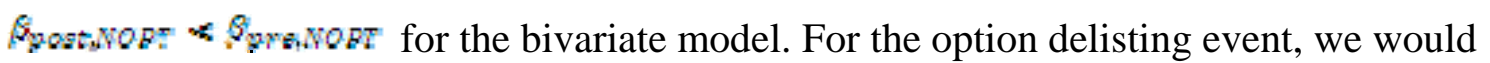
expect $\beta_{\text {post }}<\beta_{\mathrm{pre}}$ in the case of the univariate model and $\beta_{\mathrm{pont}, \mathrm{ORT}}<\beta_{\mathrm{pr}, \mathrm{ODT}}$ and $\beta_{\text {yoswon: }} \geq \beta_{\text {manort }}$ for the bivariate model. The results of the calendar time analysis are presented in Table 5.

\section{[Insert Table 5 about here]}


For the option listing events, we observe significant increases in the post-listing comovement. This evidence is consistent with the earlier results in Table 3 at all data frequencies. The results of the bivariate analysis also support the predictions of the category view of comovement as $\beta_{\mathrm{FartNOFT}} \leqslant \beta_{\mathrm{Fr}, \mathrm{NOFT}}$. Thus once an option is introduced on a stock, the stock's comovement with non-optioned stocks reduces but its comovement with other optioned stocks increases. Results for the delisting events are also consistent with those reported for the event-time analysis reported in Table 3. Although we find some significant changes in the slope coefficients in places, they do not contradict the general pattern observed earlier. As stated earlier, the results of the delisted sample must be interpreted with care due to the small sample size.

\subsection{Information diffusion versus category and habitat}

The introduction of options on a stock offers an investor the opportunity to easily short that stock even if the investor faces short selling constraints. The existence of listed options on a stock could therefore lead to greater visibility and faster adjustment to pricing. Consequently, a stock may respond more quickly to market-wide information following option listing, resulting in increases in the post-listing factor loadings. Thus, the shifts in comovement observed are also consistent with changes in the speed of information diffusion.

However, as can be seen from the results presented, shifts in comovement following option listing (in particular) occur consistently across all data frequencies. This suggests that changes in information diffusion do not fully explain the earlier results since using longer return intervals reduce the biases in coefficient estimates due to non-synchronous trading and the slow speed of price adjustment. All the same, we follow the procedure adopted in 
Barberis et al (2005) and Green and Hwang (2009) in order to directly rule out the information diffusion view.

For each stock, we re-estimate Eqs. (1) and (2) including five (two) leading and lagging returns of the portfolio of optioned stocks and non-optioned stocks using daily (weekly) returns. This approach is the Dimson (1979) adjustment technique for non-trading effects but we have also adjusted the Dimson estimates with the appropriate weights following Fowler and Rorke (1983). Thus, for each event (listing or delisting), the univariate model:

$$
R_{i, t}=\alpha_{i}+\sum_{k=-R}^{K} \beta_{i, k} R_{O P T, t+k}+a_{i, t}
$$

and the bivariate model

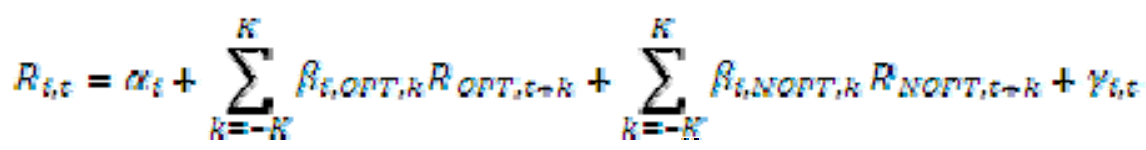

are estimated separately for each stock before and after each event, where $K=2$ for weekly returns and $K=5$ for daily returns. Thereafter, the Dimson-Fowler-Rorke (DFR) adjusted factor loadings are calculated as:

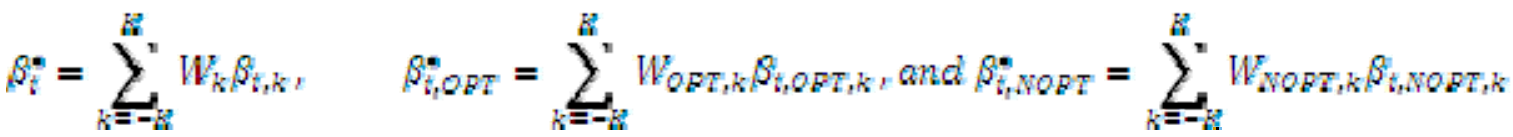

where $W_{k}, W_{\text {PET } \mathrm{K}}$ and $W_{\text {NOFT }}$ are the appropriate Fowler and Rorke (1983) adjustment weights. As the DFR factor loadings are now corrected for biases caused by speed of information diffusion, any significant shifts in the post event factor loadings would rule out the information diffusion argument as the only explanation for the earlier findings above. 
Table 6 reports the cross-sectional average change in the DFR adjusted slope coefficient for the univariate model, $\overline{\Delta \beta}$, and the cross-sectional average of the change in the $\mathrm{R}^{2}, \overline{\Delta R^{2}}$, of Eq.(5). For the bivariate model, we report the cross-sectional average change in the DFR adjusted factor loadings on the portfolio of optioned stocks, $\overline{\Delta \beta_{\mathrm{OPT}}^{*}}$, and the factor loading on the portfolio of non-optioned stocks, $\overline{\Delta \beta_{\mathrm{NOPT}}^{\mathrm{e}}}$. Over the full sample period, we find that $\overline{\Delta \beta}=$ is 0.1319 , and the change in the $\mathrm{R}^{2}, \overline{\Delta R^{2}}$, is 0.0356 . These increases are statistically significant, which further suggests that the shifts in post-event comovement are not driven by changes in the speed of information diffusion. Overall, the results in Tables 6 are largely similar, in terms of magnitude and direction, to that presented in Table 3. Also, as shown in Panels A and B of Table 7, significant changes in the respective factor loadings occur largely contemporaneously. Our results therefore support the habitat and category views, which is plausible given the increased visibility of the stock following option listing.

\section{[Insert Tables 6 and 7 about here]}

\subsection{What drives the comovement of the option listed stocks?}

In this section, we consider whether the comovement of the optioned listed stocks is driven by commonalities in trading in the underlying stocks or trading in the stock options. Since sentiment affects stock prices through trading, it is reasonable to expect a positive relationship between comovement and trading volume. ${ }^{17}$ In order to assess whether the commonality in the returns of optioned stocks is related to stock volume or options volume, we modify the univariate and bivariate regressions above (Eqs.(1) and (2)) as follows:

\footnotetext{
${ }^{17}$ We are grateful to the anonymous referee for suggesting the option volume idea.
} 


$$
\begin{aligned}
R_{i, t}= & \alpha_{i}+\beta_{i 0} R_{O P T, t}+\beta_{i, 1} D_{\text {volume }}, t, R_{O P T, t}+s_{i, t} \\
R_{i, t}= & \alpha_{i}+\beta_{t, O P T, 0} R_{O P T, t}+\beta_{t, O P T, 1} D_{\text {volume }}, t R_{O P T, t}+ \\
& \beta_{i, N O P T, 0} R_{\text {NOPT }, t}+\beta_{i, N O P T, 1} D_{\text {volume }}, t R_{N O P T, t}+\gamma_{i, t}
\end{aligned}
$$

where Dvolume $e_{i, t}$ is a dummy variable with a value of one if trading volume for stock $i$ on day $t$ belongs to the highest $30 \%$ volume bracket in a given quarter and zero otherwise. ${ }^{18}$ For convenience, we refer to the days when Dvolume $_{i, t}$ is equal to one as periods of high trading activity and the rest of the days as periods of normal trading activity. We use several trading volume measures to construct Dvolume. We use turnover by volume (VO) and dollar volume (VA) to capture trading activity in the stock market and call option volume (CVM), put option volume (PVM) and aggregate option volume (VM) to reflect trading activity in the options market. The definitions and the summary statistics of the different volume measures are shown in Table 8.

\section{[Insert Tables 8 and 9 about here]}

In this section, we are more interested in the coefficients of the interaction terms, $\beta_{i 1}$ in Eq.(8) and $\beta_{t, O P T_{1}}$ ( $\beta \mathbf{D}_{\Downarrow(L, N O P T, 1))}$ in Eq.(9). The coefficient $\beta_{i 1}$ in Eq.(8) measures the excess factor loading on the optioned portfolio during periods of high trading activity. Similarly, $\beta_{\hbar, O R T_{1}}$ ( $\mathbf{\square} \boldsymbol{\mathbf { \beth }}(t, N O P T, 1)$ ) in Eq.(9) captures the excess post-listing factor loadings of newly option listed stocks with the optioned (non-option) portfolio during periods of high trading activity. Eqs.(8) and (9) are estimated using daily returns over a period of 1 year after the option listing date. ${ }^{19}$ This analysis is based on stocks with option volume data available immediately after option listings. Only 40 of our sample stocks satisfy this criterion. If a trading volume variable contributes to the comovement of the optioned

\footnotetext{
${ }^{18}$ We also use the highest $20 \%$ and the highest $10 \%$ volume brackets to define Dvolume $e_{i, t}$ and our conclusions remain unchanged. Details of these results can be obtained from the authors.

${ }^{19}$ We repeat our analysis at both weekly and monthly frequencies and our conclusions remain unchanged. The results are available upon request.
} 
stocks, we will expect on average $\beta_{i 1}$ in Eq.(8) and $\beta_{i, 0 p T_{1}}$ in Eq.(9) to be greater than zero but $(\llbracket \beta 】(t, N O P T, 1))$ in Eq.(9) to be less than zero.

The results of the estimation are presented in Table 9 . We find that $\beta_{i 1}$ increases, on average, by $20.77 \%, 12.89 \%$ and $14.65 \%$ during periods of high CVM, PVM and VM, respectively. Similarly, the comovement of option listed stock also increases, on average, by $28.44 \%$ (25.75\%) during periods of high VO (VA). The distribution of the $\beta_{i 1}$ estimates also indicates that over $70 \%$ of the option listed stocks experience comovement increase during periods of high trading activity. Overall, the results of Eq.(8) suggest that trading activity in both option and stock markets affect the comovement of option listed stocks. Table 9 also shows that the coefficient $\beta_{i, Q P T, 2}$ in Eq.(9) is, on average, positive for all the option volume measures. However, the average $\beta_{t, O P T_{1}}$ is not statistically significant in the case of the put option volume measure. It is also interesting to note that the average $\beta_{t, Q P T, 1}$ is not significant in the cases of VO- or VA-based Dvolume. This evidence indicates that, after accounting for changes in fundamentals, the comovement of option listed stocks is not related to the volume in the underlying stocks. The average $\beta_{t, \Delta O P T_{1}}$ is not significantly different from zero when CVM, PVM or VM is used to construct Dvolume in Eq.(9). However, the average $P_{i, N O P T, 1}$ is significantly positive in the cases of VO- and VA-based Dvolume. Thus, after controlling for changes in fundamentals, the comovement of option listed stocks is positively related to the option volume measures rather than the underlying stock volume. A closer look at the results also suggests that the comovement of the option listed stocks is induced largely by the activities of call option traders. The dominance of call option traders' sentiment may be due to the fact that covered call are the most common strategies in the options markets (Lakonishok et al., 2006).

\section{Conclusion}


This study tests two important comovement theories in the context of stock option listing and delisting. The fundamentals-based theory is based on the assumptions of frictionless economy and rational investors. It attributes return comovement to the correlation in the fundamental values of the underlying stocks. The friction-based theory offers a completely different explanation. It suggests that comovement reflects the characteristics of economies with frictions or irrational behaviour.

Previous studies discover return comovement in various types of stocks. Pirinsky and Wang (2006) show that the fundamentals-based theory cannot explain the comovement in the returns of stocks traded in the same geographical area. Barbaris et al. (2005) attribute the comovement in the returns of S\&P 500 index stocks to the friction-based theory. Green and Hwang (2009) claim that Pirinsky and Wang's (2006) results may be biased as they were not able to fully control for the impact of economic influences, such as local labour markets, on their results. The findings of Barbaris et al. (2005) may also be influenced by the large sums invested in the S\&P 500 index funds. Green and Hwang (2009) use stock splits to test the friction-based theory. They argue that stock splits offer a relatively clean test of categorybased investing as the splits induce large changes in nominal prices without affecting firm's fundamentals. The authors show that stocks that undergo split exhibit more comovement with low-priced stocks and less comovement with high-priced stocks.

In this study, we examine the return comovement around the listing and delisting of stock option contracts. Since the option listing decision in LIFFE is based on public information, such as firm size and its popularity among investors, option listing (delisting) should not convey any news on the firm's fundamentals. Thus, option listing and delisting events offer another relatively clean test of friction-based theory. Our analysis involves measuring the shifts in newly option listed (delisted) stocks' comovement with the index of option listed (delisted) stocks before and after option listing (delisting). 
Our evidence supports the predictions of the friction-based theory of comovement. We show that newly option listed stocks experience an increase in comovement with the index of optioned stocks and a decrease in comovement with the rest of the stocks. Similarly, stocks that undergo option delisting exhibit a decrease in comovement with the index of optioned stocks and an increase in comovement with the rest of the stocks.

To ensure that our comovement results are not driven by changes in fundamentals, we repeat our analysis on a sample of matched stocks. We match each option listed stock with a control stock in the same size decile at the time of listing. While option listed stocks exhibit more comovement with the portfolio of optioned stocks and less with the portfolio of nonoptioned stocks, the matched sample exhibits less comovement with the portfolio of optioned stocks and more comovement with the portfolio of non-optioned stocks. Thus, the matched sample analysis shows that the post-listing comovement of the optioned stocks is not driven by the changes in the fundamentals of these stocks. The same conclusion is drawn after applying the matching sample analysis on the option delisted stocks.

We also examine the robustness of our findings by using a calendar time portfolio approach to account for cross-sectional dependences in our sample. We show that the calendar time portfolio approach produces similar results to the event time portfolio approach. Furthermore, we use a technique proposed by Dimson (1979) to distinguish between category and habitat views and the information diffusion view of the friction-based comovement theory. Our analysis suggests that the comovement of option listed stocks is more likely to be driven by category and habitat effects than the information diffusion effect. The relatively large comovement between option listed stocks is even larger during periods with high option trading. This linkage suggests that commonality in option trading may serve to induce a commonality in stock price movements, which supports a category or habitat 
view of comovement. Further analysis reveals that the comovement of optioned stocks is likely to be driven by commonalities induced by call option traders. 


\section{References:}

161-199.

Barberis, N., Shleifer, A., 2003. Style investing. Journal of Financial Economics 68,

Barberis, N., Shleifer, A., and Wurgler, J., 2005. Comovement. Journal of Financial Economics 75, 283-317.

Bodurtha, J.N, Kim, D., and Lee, C.M.C, 1995. Closed-end country funds and U.S. market sentiment. Review of Financial Studies 8, 879-718.

Coakley, J, and Kougoulis, P, 2005. Comovement and FTSE 100 Index Changes (February 2005). EFMA 2004 BASEL MEETINGS; Essex Finance Centre Discussion Paper No. 04/13. Available at SSRN: http://ssrn.com/abstract=676002

Detemple, J., Selden, L., 1991. A general equilibrium analysis of option and stock market interactions. International Economic Review 32, 279-303.

Dimson, E., 1979. Risk measurement when shares are subject to infrequent trading. Journal of Financial Economics 7, 197-227.

Edwards, F. R.,1988. Futures trading and cash volatility: Stock index and interest rate futures. Journal of Futures Markets 8, 421-439.

Faff, R., and Hillier, D., 2005. Complete markets, informed trading and equity option introductions. Journal of Banking and Finance 29, 1359-1384.

Figlewski, S., 1981. Futures trading and volatility in the GNMA futures. Journal of Finance 36, 445-456.

Fowler, D., and Rorke, C.H., 1983. Risk measurement when shares are subject to infrequent trading. Journal of Financial Economics 12, 279-283.

Froewiss, K., 1978. GNMA futures: Stabilising or destabilising? Economic Review (pp.20-29). Federal Reserve Bank of San Francisco.

Gorton, G.B. and Pennacchi, G.G., 1993. Security baskets and index-linked securities. Journal of Business 66, 1-27.

Green, B., and Hwang, H., 2009. Price-based return comovement. Journal of Financial Economics 93, 37-50.

Greenwood, R., 2008. Excess Comovement of Stock Returns: Evidence from crosssectional variation in Nikkei 225 weights. Review of Financial Studies 21, 1153-1186.

Hardouvelis, G.A., La Porta, R., and Wizman, T.A., 1994. What moves the discount on country equity funds? Working paper 4571, National Bureau of Economic Research. 
Hamill, P.A., Opong, K. K. and McGregor, P., 2002. Equity option listing in the UK: A comparison of market-based research methodologies. Journal of Empirical Finance 9, 91108.

Harris, L., 1989. S\&P 500 cash stock price volatilities. Journal of Finance, 44, 11551175.

Kumar, A., and Lee, C.M.C., 2006. Retail investor sentiment and return comovements. Journal of Finance 61, 2451-2486.

Lakonishok, J., Lee, I., Pearson, N.D., and Poteshman, A.M., 2006. Option market activity. The Review of Financial Studies, 20, 813-857.

Lee, C., Shleifer, A., and Thaler, R., 1991. Investor sentiment and the closed-end fund puzzle. Journal of Finance 46, 75-110.

Mayhew, S. and Mihov, V., 2004. How do exchanges select stocks for option listing? Journal of Finance 59, 447-471.

Mazouz, K. and Bowe, M., 2006. The volatility effect of futures trading: Evidence from LSE traded stocks listed as individual equity futures contracts on LIFFE. International Review of Financial Analysis, 15, 1-20.

Mazouz, K., 2004. The effect of CBOE option listing on the volatility of NYSE traded stocks: A time-varying variance approach. Journal of Empirical Finance, 11, 695-708.

Ni, X.S., Pearson, N.D., and Poteshman, A.M., 2005. Stock price clustering on option expiration dates. Journal of Financial Economics, 78, 49-87.

Pindyck, R., and Rotemberg, J., 1993. The comovement of stock prices. Quarterly Journal of Economics 108, 1073-1104.

Pirinsky, C.A, and Wang, Q., 2006. Does corporate headquarters location matter for stock returns? Journal of Finance 61, 1991-2015.

Pirinsky, C.A., and Wang, Q., 2004, Institutional investors and the comovement of equity prices. Working paper, George Washington University.

Roll, R., Schwartz, E., and Subrahmanyam, A., 2010. O/S: The relative trading activity in options and stock. Journal of Financial Economics, 96, 1-17.

Sahlstrom, P., 2001. Impact of stock option listings on return and risk characteristics in Finland. International Review of Financial Analysis, 10, 19-36.

Simpson, W., and Ireland, T., 1985. The impact of futures trading on the cash market for treasury bills. Journal of Financial and Quantitative Analysis, 20, 371-379.

Vijh, A., 1994. S\&P 500 trading strategies and stock betas. Review of Financial Studies 7, 215-251. 
Zhen, S., 2007. Time series cross-correlation analysis of comovement between twin styles. Working paper, Arizona State University. 
Table 1: Number of new stock option listings and delistings by year

This table shows the number of new stock option listings and delistings per year.

\begin{tabular}{|l|c|c|c|c|c|c|c|c|}
\hline Year & $\begin{array}{c}\text { Number } \\
\text { of } \\
\text { Listings }\end{array}$ & $\begin{array}{c}\text { Number } \\
\text { of } \\
\text { Delistings }\end{array}$ & Year & $\begin{array}{c}\text { Number } \\
\text { of } \\
\text { Listings }\end{array}$ & $\begin{array}{c}\text { Number } \\
\text { of } \\
\text { Delistings }\end{array}$ & Year & $\begin{array}{c}\text { Number } \\
\text { of } \\
\text { Listings }\end{array}$ & $\begin{array}{c}\text { Number } \\
\text { of } \\
\text { Delistings }\end{array}$ \\
\hline 1978 & 14 & 0 & 1988 & 9 & 1 & 1998 & 4 & 3 \\
\hline 1979 & 1 & 0 & 1989 & 7 & 2 & 1999 & 12 & 2 \\
\hline 1980 & 4 & 3 & 1990 & 5 & 4 & 2000 & 19 & 9 \\
\hline 1981 & 1 & 0 & 1991 & 4 & 6 & 2001 & 8 & 11 \\
\hline 1982 & 0 & 0 & 1992 & 1 & 4 & 2002 & 4 & 9 \\
\hline 1983 & 5 & 0 & 1993 & 8 & 4 & 2003 & 12 & 9 \\
\hline 1984 & 4 & 0 & 1994 & 0 & 0 & 2004 & 2 & 2 \\
\hline 1985 & 6 & 0 & 1995 & 2 & 1 & 2005 & 6 & 2 \\
\hline 1986 & 9 & 2 & 1996 & 6 & 11 & 2006 & 4 & 5 \\
\hline 1987 & 17 & 1 & 1997 & 11 & 4 & 2007 & 0 & 6 \\
\hline Total & & & & & & & 185 & 101 \\
\hline
\end{tabular}


Table 2: Descriptive statistics of the changes in the univariate and bivariate betas and change in the univariate R-square.

The sample includes stock options listings between 1986 and 2007 that have sufficient return data before and after listing, and were not involved in mergers and acquisitions. For each stock in the sample, the univariate model:

and the bivariate model

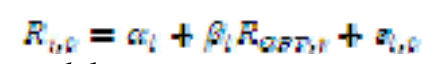

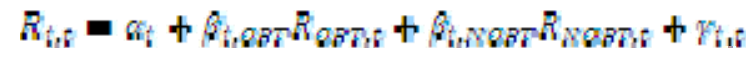

are estimated separately for the pre- and post-listing period. The table presents the cross-sectional distribution of the changes in the univariate slope coefficient, $\mathbf{M} /$, the changes in the $\mathrm{R}^{2}, \Delta \boldsymbol{R}^{2}$, and the changes in the bivariate slope coefficients, $\Delta \beta_{a s s}$ and $\Delta \beta_{\text {Nass }}$. The table reports the number of stocks in the sample (N), mean, standard deviation (StDev), minimum, first quartile (Q1), median, third quartile (Q3), maximum and the proportion of positive changes $(\%>0)$. An asterisk $(*)$ in the last column indicates the observed proportion of positive changes $(\%>0)$ is significantly greater (or less) than 0.5 .

\section{Panel A: Daily Returns}

$\Delta \beta$

$$
\begin{gathered}
\Delta R^{2} \\
\Delta \beta_{O B T} \\
\Delta \beta_{N O B T}
\end{gathered}
$$

Panel B: Weekly Returns

$\Delta \beta$

$$
\begin{gathered}
\Delta R^{2} \\
\Delta \beta_{O B T} \\
\Delta \beta_{X O E T}
\end{gathered}
$$

Panel C: Monthly Returns

$\Delta \beta$

$$
\begin{gathered}
\Delta R^{2} \\
\Delta \beta_{O B T} \\
\Delta \beta_{N O B T}
\end{gathered}
$$

\begin{abstract}
Mean
\end{abstract}
0.1082

0.0247

0.3147

$-0.2518$

0.1240

0.0414

0.2745

$-0.1684$

0.0847

0.0151

0.3626

$-0.3013$

\begin{abstract}
StDev
Minimum
\end{abstract}

\subsection{5}

0.1299

0.5363

0.6505

0.4729

0.1808

0.7032

0.7261

0.4519

0.2258

1.1179

1.0454

$-0.6586$

$-0.2399$

$-0.6609$

$-1.6158$

$-0.9275$

$-0.3497$

$-1.0688$

$-1.5713$

$-1.0344$

$-0.5191$

$-1.9562$

$-1.8747$

\begin{abstract}
Q1
\end{abstract}
$-0.1651$

$-0.0965$

$-0.1484$

$-0.7498$

$-0.2406$

$-0.1239$

$-0.2446$

$-0.8829$

$-0.1825$

$-0.1689$

$-0.3806$

$-1.0500$
Median

\subsection{9}

0.0196

0.3071

$-0.2312$

0.0425

0.0424

0.3017

$-0.2329$

0.0577

$-0.0049$

0.2112

$-0.2957$
Q3

Maximum

$\%>0$

$\begin{array}{lll}0.2934 & 1.4278 & 0.636^{\star \star \star} \\ 0.1201 & 0.3766 & 0.606^{\star \star} \\ 0.7449 & 1.4312 & 0.697^{\star \star \star} \\ 0.2373 & 0.8668 & 0.384^{\star \star}\end{array}$

$\begin{array}{lll}0.3756 & 1.4391 & 0.586^{* *}\end{array}$

$0.1855 \quad 0.3661 \quad 0.586^{* \star}$

$0.7723 \quad 1.8406 \quad 0.636^{\star \star *}$

$0.2583 \quad 1.351 \quad 0.364^{* * *}$

$\begin{array}{lll}0.3834 & 1.2943 & 0.566^{*}\end{array}$

$\begin{array}{lll}0.1749 & 0.4660 & 0.489\end{array}$

$\begin{array}{lll}1.0341 & 2.1220 & 0.602 \text { ** }\end{array}$

$\begin{array}{lll}0.5193 & 1.7324 & 0.330^{\star * \star}\end{array}$ 
Table 3: Changes in comovement of stocks with listed options before and after listing and delisting

This table presents changes in the slope coefficient and the $\mathrm{R}^{2}$ of regressions of returns of stocks introducing stock options and stocks delisting stock options on returns of portfolio of stocks with listed options and portfolio of stocks with no listed options. The sample includes stocks options listings and deletions between 1986 and 2007 that have sufficient return data before and after listing or delisting and were not involved in mergers and acquisitions. For each event (listing or delisting), the univariate model:

and the bivariate model

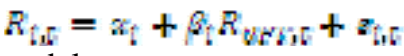

$$
R_{t, t}=\alpha_{t}+\beta_{t, O B T} R_{O B D, t}+\beta_{t, N O B T} R_{\text {NOBD, }}+\gamma_{t, t}
$$

are separately estimated for the pre- and post-event period for each stock, $i . \mathrm{R}_{\mathrm{OPT}}$ is the value-weighted returns on the portfolio of stocks with listed options. $\mathrm{R}_{\mathrm{NOPT}}$ is the value-weighted returns on the portfolio of stocks with no listed options. For the univariate regression model, we report the mean change in slope coefficient around the event, $\overline{\Delta \beta}$ and the mean change in $\mathrm{R}^{2}, \overline{\Delta \mathbf{R}^{2}}$. For the bivariate regression model, we report the mean change in slope coefficient $\beta_{i, O P T}$ around the event, $\overline{\Delta \beta_{\mathrm{OPT}}}$ and the mean change in slope coefficient $\beta_{i, N O P T}, \overline{\Delta \beta_{\text {NOFT }}}$.

The pre-event and post-event estimation periods are 12, 24 and 36 months before and after the event month for the analysis using daily, weekly and monthly returns, respectively. Panels A, B, and C show results for daily, weekly, and monthly returns, respectively. The t-values (shown in parenthesis) are based on standard errors

\begin{tabular}{|c|c|c|c|c|c|c|}
\hline & & \multirow[b]{2}{*}{$\mathrm{N}$} & \multicolumn{2}{|c|}{ Univariate } & \multicolumn{2}{|c|}{ Bivariate } \\
\hline & & & $\overline{\Delta Q}$ & $\overline{\Delta R^{2}}$ & \multicolumn{2}{|c|}{$\begin{array}{lc} & \text { Bivariate } \\
\overline{\Delta \beta_{\text {UNi }}} & \overline{\Delta \beta_{\text {NuN }}}\end{array}$} \\
\hline \multicolumn{7}{|c|}{ Panel A: Daily Returns } \\
\hline \multirow[t]{6}{*}{ Listing } & $1986-2007$ & 99 & $0.1082^{\star \star \star}$ & $0.0247^{\star \star}$ & $0.3147^{\star \star \star}$ & $-0.2518^{\star \star \star}$ \\
\hline & & & $(2.5513)$ & (1.8209) & $(6.0112)$ & $(-3.8415)$ \\
\hline & $1986-1998$ & 48 & -0.0217 & 0.0080 & $0.2685^{\star \star \star}$ & $-0.3832^{\star \star \star}$ \\
\hline & & & $(-0.4530)$ & (0.4906) & (3.5680) & $(-5.4134)$ \\
\hline & $1999-2007$ & 51 & $0.2305^{\star \star \star}$ & $0.0403^{* *}$ & $0.3581^{* * *}$ & -0.1281 \\
\hline & & & $(3.5602)$ & (1.8974) & $(4.9018)$ & $(-1.2061)$ \\
\hline \multirow[t]{2}{*}{ Delisting } & $1986-2007$ & 20 & -0.0413 & 0.0027 & $-0.4356^{\star \star \star}$ & $0.5539^{* * *}$ \\
\hline & & & $(-0.4996)$ & (0.1928) & $(-3.0065)$ & (3.5839) \\
\hline \multicolumn{7}{|c|}{ Panel B: Weekly Returns } \\
\hline \multirow[t]{6}{*}{ Listing } & $1986-2006$ & 99 & $0.1240^{\star \star}$ & $0.0414^{\star \star *}$ & $0.2745^{\star \star \star}$ & $-0.1684^{\star \star \star}$ \\
\hline & & & (2.1806) & $(2.6792)$ & (3.4737) & $(-2.4627)$ \\
\hline & $1986-1998$ & 48 & -0.0174 & $0.0325^{\star \star}$ & $0.1516^{\star}$ & $-0.2061^{\star \star}$ \\
\hline & & & $(-0.3747)$ & $(2.0226)$ & (1.6253) & $(-2.0802)$ \\
\hline & $1999-2006$ & 51 & $0.2571^{\star \star \star}$ & $0.0499 \star \star$ & $0.3901^{\star \star *}$ & $-0.1329 * *$ \\
\hline & & & $(2.6164)$ & (1.9140) & (3.1330) & $(-1.3969)$ \\
\hline \multirow[t]{2}{*}{ Delisting } & $1986-2006$ & 20 & $-0.1571^{*}$ & -0.0214 & $-0.2367^{\star}$ & 0.0820 \\
\hline & & & $(-1.4480)$ & $(-1.0406)$ & $(-1.4084)$ & $(0.3601)$ \\
\hline
\end{tabular}
clustered by month to adjust for any possible dependencies across the sample. 
Table 3: Changes in comovement of stocks with listed options before and after listing and delisting (continued)

\begin{tabular}{|c|c|c|c|c|c|c|}
\hline \multicolumn{7}{|c|}{ Panel C: Monthly Returns } \\
\hline \multirow[t]{6}{*}{ Listing } & $1986-2005$ & 88 & $0.0847^{\star *}$ & 0.0170 & $0.3626^{* \star *}$ & $-0.3013^{* \star *}$ \\
\hline & & & $(1.7490)$ & $(0.6823)$ & $(3.1400)$ & $(-2.7925)$ \\
\hline & $1986-1998$ & 45 & -0.0480 & 0.0067 & 0.1085 & $-0.2112^{*}$ \\
\hline & & & $(-0.7128)$ & $(0.2488)$ & $(0.7162)$ & $(-1.2945)$ \\
\hline & $1999-2005$ & 43 & $0.1919^{\star \star \star}$ & $0.0342^{*}$ & $0.5254^{\star \star *}$ & $-0.3799 * \star \star$ \\
\hline & & & (2.8501) & $(1.3767)$ & (2.8602) & $(-2.8981)$ \\
\hline Delisting & $1986-2005$ & 17 & -0.0726 & -0.0080 & -0.1704 & 0.1272 \\
\hline & & & $(-0.9254)$ & $(-0.1683)$ & $(-0.5558)$ & $(0.6048)$ \\
\hline
\end{tabular}

${ }^{\star * *},{ }^{\star *}$, and ${ }^{*}$ denote statistical significance (one-tail t-test) at the $1 \%, 5 \%$, and $10 \%$ level respectively 
Table 4: Excess comovement of stocks with listed options before and after listing and delisting relative to control sample of firms

This table presents the excess changes in the factor loadings and the $\mathrm{R}^{2}$ of regressions of returns of stocks introducing stock options and stocks delisting stock options on returns of portfolio of optioned stocks and portfolio of non-optioned stocks relative to the corresponding changes in a sample of control firms. The sample includes stock options listings and deletions from between 1986 and 2007 that have sufficient return data before and after listing or delisting and were not involved in mergers and acquisitions. Each stock in the option sample is matched with a control stock of similar size. For each event (listing or delisting), the univariate model:

and the bivariate model

$$
R_{t, t}=\alpha_{t}+\beta_{t} R_{\text {OBS }, t}+\sigma_{t, t}
$$

$$
R_{t, t}=\alpha_{t}+\beta_{t, O R T} R_{O R S t}+\beta_{t, N O R S} R_{\text {NORSt }}+\gamma_{t t}
$$

are separately estimated for the pre- and post-event period for each stock, $i$ in the optioned sample and the control sample. $\mathrm{R}_{\mathrm{OPT}}$ is the value-weighted returns on the portfolio of stocks with listed options. $\mathrm{R}_{\mathrm{NOPT}}$ is the value-weighted returns on the portfolio of stocks with no listed options. For the univariate regression model, we report the mean excess change in slope coefficient around the event in the optioned sample relative to the corresponding change in the control sample, $\overline{\Delta \Delta \beta}$ and the mean excess change in $\mathrm{R}^{2}, \overline{\Delta \Delta R^{2}}$. For the bivariate regression model, we report the mean excess change in the slope coefficient $\beta_{i, O P T}$ around the event in the optioned stocks relative to the control stocks $\overline{\Delta \Delta \beta_{O B T}}$, and the corresponding mean excess change in the slope coefficient $\beta_{i, N O P T}, \overline{\triangle \triangle \beta_{\text {NORT }}}$. The pre-event and post-event estimation periods are 12, 24 and 36 months before and after the event month for the analysis using daily, weekly and monthly returns, respectively. Panels A, B, and $\mathrm{C}$ show results for daily, weekly, and monthly returns, respectively. The t-values (shown in parenthesis) are

\begin{tabular}{|c|c|c|c|c|c|c|}
\hline & & \multirow[b]{2}{*}{$\mathbf{N}$} & \multicolumn{2}{|c|}{ Univariate } & \multicolumn{2}{|c|}{ Bivariate } \\
\hline & & & $\overline{\Delta \Delta Q}$ & $\overline{\Delta \Delta R^{2}}$ & $\overline{\triangle \Delta G_{O D Z}}$ & $\overline{\Delta \Delta \beta_{\text {NGRT }}}$ \\
\hline \multicolumn{7}{|c|}{ Panel A: Daily Returns } \\
\hline \multirow[t]{6}{*}{ Listing } & $1986-2007$ & 99 & 0.0708 & 0.0074 & $0.3292^{\star \star \star}$ & $-0.4102^{* * *}$ \\
\hline & & & $(1.2287)$ & $(0.5037)$ & $(4.3880)$ & $(-4.7814)$ \\
\hline & $1986-1998$ & 48 & -0.0639 & 0.0075 & $0.2969 * \star \star$ & $-0.4784^{\star \star \star}$ \\
\hline & & & $(-1.3356)$ & $(0.3887)$ & (2.5581) & $(-3.9142)$ \\
\hline & $1999-2007$ & 51 & $0.1975^{\star *}$ & 0.0073 & $0.3853^{* * *}$ & $-0.3460^{\star \star \star}$ \\
\hline & & & $(2.0605)$ & $(0.3271)$ & (3.7495) & $(-2.8146)$ \\
\hline \multirow[t]{2}{*}{ Delisting } & $1986-2007$ & 20 & -0.0752 & 0.0039 & -0.1717 & 0.1281 \\
\hline & & & $(-0.6468)$ & $(0.1317)$ & $(-0.8700)$ & $(0 . .4061)$ \\
\hline \multicolumn{7}{|c|}{ Panel B: Weekly Returns } \\
\hline \multirow{6}{*}{ Listing } & $1986-2006$ & 99 & 0.0142 & 0.0101 & $0.2109 \star \star$ & $-0.2620^{\star \star \star}$ \\
\hline & & & $(0.1702)$ & $(0.2767)$ & (1.9980) & $(-2.5536)$ \\
\hline & $1986-1998$ & 48 & -0.1322 & -0.0231 & 0.0794 & $-0.2354^{*}$ \\
\hline & & & $(-1.5028)$ & $(-0.3223)$ & $(0.6250)$ & $(-1.4230)$ \\
\hline & $1999-2006$ & 51 & $0.1519^{\star \star}$ & $0.0413^{*}$ & $0.3346^{\star \star}$ & $-0.2870^{\star *}$ \\
\hline & & & (1.6903) & $(1.3651)$ & (2.1214) & $(-2.3897)$ \\
\hline
\end{tabular}
based on standard errors clustered by month to adjust for any possible dependencies across the sample. 


\begin{tabular}{|c|c|c|c|c|c|c|}
\hline Delisting & $1986-2006$ & 20 & $\begin{array}{l}-0.1073 \\
(-0.4348)\end{array}$ & $\begin{array}{l}0.0372 \\
(1.1722)\end{array}$ & $\begin{array}{l}-0.2019 \\
(-0.8675)\end{array}$ & $\begin{array}{l}0.0472 \\
(0.1143)\end{array}$ \\
\hline
\end{tabular}

Table 4: Excess comovement of stocks with listed options before and after listing and delisting relative to control sample of firms (continued)

Panel C: Monthly Returns

\begin{tabular}{|c|c|c|c|c|c|c|}
\hline \multirow[t]{3}{*}{ Listing } & $1986-2005$ & 88 & $\begin{array}{l}0.0736 \\
(1.0426)\end{array}$ & $\begin{array}{l}0.0052 \\
(0.2541)\end{array}$ & $\begin{array}{l}0.1925^{\star \star \star} \\
(2.6329)\end{array}$ & $\begin{array}{l}-0.1436^{\star *} \\
(-1.7711)\end{array}$ \\
\hline & $1986-1998$ & 45 & $\begin{array}{l}-0.0352 \\
(-0.4156)\end{array}$ & $\begin{array}{l}0.0019 \\
(0.1264)\end{array}$ & $\begin{array}{l}0.0891 \\
(0.8866)\end{array}$ & $\begin{array}{l}-0.0478 \\
(-0.3073)\end{array}$ \\
\hline & $1999-2005$ & 43 & $\begin{array}{l}0.1874^{\star *} \\
(2.2064)\end{array}$ & $\begin{array}{l}0.0087 \\
(0.5912)\end{array}$ & $\begin{array}{l}0.3110^{\star \star *} \\
(3.5293)\end{array}$ & $\begin{array}{l}-0.2438^{\star *} \\
(-2.3056)\end{array}$ \\
\hline Delisting & $1986-2005$ & 17 & $\begin{array}{l}-0.1880 \\
(-1.1476)\end{array}$ & $\begin{array}{l}-0.0195 \\
(-0.2541)\end{array}$ & $\begin{array}{l}-0.2576^{\star} \\
(-1.3316)\end{array}$ & $\begin{array}{l}0.0641 \\
(0.6870)\end{array}$ \\
\hline
\end{tabular}

${ }^{* \star \star},{ }^{* *}$, and ${ }^{*}$ denote statistical significance (one-tail t-test) at the $1 \%, 5 \%$, and $10 \%$ level respectively 
Table 5: Calendar time estimates of changes in comovement of stocks with listed options before and after listing and delisting

This table presents changes in the factor loadings of the regressions of the calendar time post-event portfolio returns and the calendar time pre-event portfolio returns on returns of the portfolio of optioned stocks and the portfolio of non-optioned stocks. We construct two calendar time portfolios, a pre-event portfolio and a postevent portfolio. The pre-event portfolio return, at time $t,{ }^{R}, s, t$, , is the equally weighted average return of all stocks that will introduce an option during the event period (12 months for daily returns, 24 months for weekly returns, and 36 months for monthly returns) and the post-event portfolio return at time $t,{ }_{\text {post, }}$, is the equally weighted average return of all stocks that introduced an option during the event period. We require that, for inclusion in the calendar-time analysis, the portfolio at time t should contain at least two stocks. For each event (listing or delisting), the univariate models:

and

$$
R_{p r s, t}=\alpha_{p e t}+\beta_{p r q} R_{Q B Z, t}+\varepsilon_{p r e, t}
$$

and the bivariate models

$$
R_{\text {pesst }}=\alpha_{\text {pess }}+\beta_{\text {poss }} R_{\text {QEN }}+\pi_{\text {pess, }}
$$

and

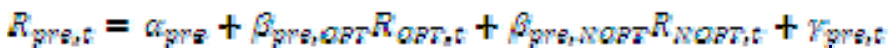

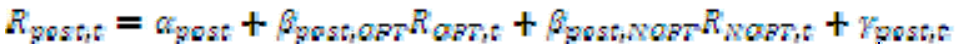

are separately estimated. $R_{\mathrm{OPT}}$ is the value-weighted returns on the portfolio of stocks with listed options. $\mathrm{R}_{\mathrm{NOPT}}$ is the value-weighted returns on the portfolio of stocks with no listed options. For the univariate regression model, we report the difference in the slope coefficients $\beta_{p o s t}$ and $\beta_{p r e}, \Delta \beta$. For the bivariate regression

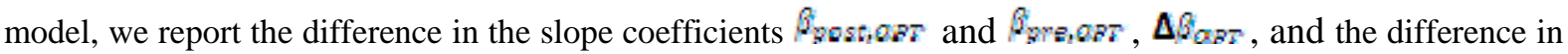

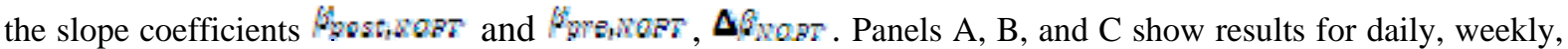

\begin{tabular}{|c|c|c|c|c|c|}
\hline & & \multirow[b]{2}{*}{$\mathbf{N}$} & \multirow[t]{2}{*}{ Univariate } & \multicolumn{2}{|c|}{ Bivariate } \\
\hline & & & & $\Delta \beta_{O E T}$ & $\Delta Q_{\text {XYET }}$ \\
\hline \multicolumn{6}{|c|}{ Panel A: Daily Returns } \\
\hline \multirow[t]{6}{*}{ Listing } & $1986-2007$ & 4333 & $0.1319^{\star * *}$ & $0.3554^{\star * \star}$ & $-0.3163^{* *}$ \\
\hline & & & (3.3956) & $(2.7505)$ & $(-2.1726)$ \\
\hline & $1986-1998$ & 2521 & 0.0163 & $0.2357^{\star \star}$ & $-0.3034^{\star *}$ \\
\hline & & & (0.3163) & (1.6576) & $(-1.6669)$ \\
\hline & $1998-2007$ & 1812 & $0.2433^{\star \star *}$ & $0.4734^{\star \star \star}$ & $-0.3567^{\star *}$ \\
\hline & & & (4. 9866) & (6.3902) & $(-3.5570)$ \\
\hline \multirow[t]{2}{*}{ Delisting } & $1986-2007$ & 1268 & -0.1066 & $-0.6138^{\star \star \star}$ & $0.4105^{\star *}$ \\
\hline & & & $(-1.1393)$ & $(-3.6919)$ & $(1.8660)$ \\
\hline \multicolumn{6}{|c|}{ Panel B: Weekly Returns } \\
\hline \multirow[t]{6}{*}{ Listing } & $1986-2006$ & 1178 & $0.1280^{\star \star}$ & $0.3389^{\star * \star}$ & $-0.3165^{\star \star \star}$ \\
\hline & & & $(1.7291)$ & (2.8748) & $(-2.3180)$ \\
\hline & $1986-1998$ & 708 & -0.0598 & $0.1757^{\star}$ & $-0.3420^{\star \star *}$ \\
\hline & & & $(-0.9594)$ & $(1.5915)$ & $(-2.1285)$ \\
\hline & $1999-2006$ & 470 & $0.3363^{\star \star \star}$ & $0.5361^{\star \star \star}$ & $-0.3203^{* * *}$ \\
\hline & & & (2.9959) & (3.8552) & $(-2.4375)$ \\
\hline
\end{tabular}
and monthly returns, respectively. The t-values (shown in parenthesis) are based on standard errors clustered by month to adjust for any possible dependencies across the sample. 


\begin{tabular}{|c|c|c|c|c|c|}
\hline Delisting & $1986-2006$ & 490 & $\begin{array}{c}-0.3001^{\star *} \\
(-2.2363)\end{array}$ & $\begin{array}{c}-0.2669 * * \\
(-1.7362)\end{array}$ & $\begin{array}{r}0.0309 \\
(0.2599)\end{array}$ \\
\hline
\end{tabular}

Table 5: Calendar time estimates of changes in comovement of stocks with listed options before and after listing and delisting (continued)

\begin{tabular}{|c|c|c|c|c|c|}
\hline \multicolumn{6}{|c|}{ Panel C: Monthly Returns } \\
\hline Listing & $1986-2005$ & 276 & $\begin{array}{c}0.0959^{*} \\
(1.4873)\end{array}$ & $\begin{array}{r}0.4575^{\star * *} \\
(2.9783)\end{array}$ & $\begin{array}{r}-0.3597^{\star * \star} \\
(-3.0112)\end{array}$ \\
\hline & $1986-1998$ & 163 & $\begin{array}{r}-0.0398 \\
(-1.0991)\end{array}$ & $\begin{array}{c}0.2937^{\star \star} \\
(2.0153)\end{array}$ & $\begin{array}{r}-0.3934^{\star \star \star} \\
(-2.7457)\end{array}$ \\
\hline & $1999-2005$ & 113 & $\begin{array}{r}0.3035^{\star \star *} \\
(2.4451)\end{array}$ & $\begin{array}{r}0.5431^{* * *} \\
(2.4829)\end{array}$ & $\begin{array}{l}-0.3085^{\star} \\
(-1.4134)\end{array}$ \\
\hline Delisting & $1986-2005$ & 164 & $\begin{array}{c}-0.5848^{* *} \\
(-2.0873)\end{array}$ & $\begin{array}{r}-0.6616^{\star * *} \\
(-2.6382)\end{array}$ & $\begin{array}{r}0.0191 \\
(0.0560)\end{array}$ \\
\hline
\end{tabular}

${ }^{* \star *},{ }^{* *}$, and * denote statistical significance (one-tail t-test) at the $1 \%, 5 \%$, and $10 \%$ level respectively 
Table 6: Changes in comovement of stocks with listed options before and after listing and delisting after adjusting for speed of information diffusion

For each event (listing or delisting), the univariate model:

$R_{t, t}=\alpha_{t}+\sum_{b=-K}^{K} \beta_{t, 2} R_{a s z, t+2}+s_{t, t}$

and the bivariate model

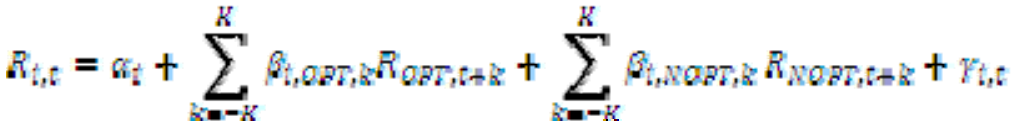

are estimated separately for each stock before and after each event, where $K=2$ for weekly returns and $K=5$ for daily returns. Thereafter, the Dimson-Fowler-Rorke (DFR) adjusted factor loadings are calculated as:

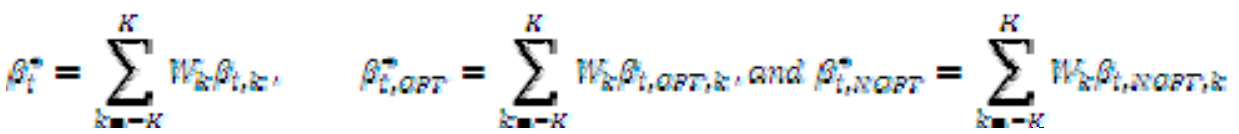

$\overline{\Delta 6}^{*}$ is the cross-sectional average change in the DFR adjusted slope coefficient for the univariate model, and $\overline{\Delta R^{\mathbf{2}}}$ is the cross-sectional average of the change in the $\mathrm{R}^{2}$ of Eq.(5). For the bivariate model, , $\overline{\Delta / F_{O F T}}$, is the cross-sectional average change in the DFR adjusted factor loading on the portfolio of optioned stocks, $\overline{\Delta \theta_{0 \mathrm{FT}}}$, and $\overline{\Delta \beta_{\mathrm{NOPT}}}$ is the factor loading on the portfolio of non-optioned stocks. We report results for the full sample period and the two subperiods. The t-values (shown in parenthesis) are based on standard errors clustered by month to adjust for any possible dependencies across the sample.

\begin{tabular}{|c|c|c|c|c|c|c|}
\hline & & & \multicolumn{2}{|c|}{ Univariate } & \multicolumn{2}{|c|}{ Bivariate } \\
\hline & & $\mathbf{N}$ & $\overline{\Delta 3^{5}}$ & $\overline{\Delta R^{2}}$ & $\overline{\Delta \beta_{Q B T}^{*}}$ & $\overline{\Delta \beta_{\text {XOB }}^{*}}$ \\
\hline \multicolumn{7}{|c|}{ Panel A: Daily Returns } \\
\hline \multirow[t]{6}{*}{ Listing } & $1986-2007$ & 99 & $0.1319 * \star$ & $0.0356^{\star \star \star}$ & $0.2490^{\star *}$ & -0.0915 \\
\hline & & & $(1.7354)$ & $(2.6408)$ & $(1.7190)$ & $(-0.6503)$ \\
\hline & $1986-1998$ & 48 & 0.0756 & 0.0097 & 0.0001 & 0.0601 \\
\hline & & & $(0.9473)$ & (0.5518) & $(0.0030)$ & $(0.3394)$ \\
\hline & $1999-2007$ & 51 & $0.1870^{\star}$ & $0.0610^{\star \star \star}$ & $0.4830^{\star \star}$ & -0.2341 \\
\hline & & & $(1.4590)$ & $(3.0627)$ & $(2.3511)$ & $(-1.0830)$ \\
\hline \multirow[t]{2}{*}{ Delisting } & $1986-2007$ & 20 & $-0.2760^{\star \star}$ & 0.0076 & $-0.7926^{\star \star \star}$ & $0.6089 * \star \star$ \\
\hline & & & $(-2.0950)$ & $(0.5283)$ & $(-4.7448)$ & $(2.6253)$ \\
\hline \multicolumn{7}{|c|}{ Panel B: Weekly Returns } \\
\hline \multirow[t]{4}{*}{ Listing } & $1986-2006$ & 99 & 0.0468 & $0.0479 * \star \star$ & $0.3516^{\star \star}$ & $-0.3096^{\star *}$ \\
\hline & & & $(0.5480)$ & (3.1925) & $(2.2533)$ & $(-2.2050)$ \\
\hline & $1986-1998$ & 48 & -0.1166 & $0.0311^{\star \star}$ & $0.2939 *$ & $-0.3836^{\star *}$ \\
\hline & & & $(-1.2109)$ & (1.9869) & $(1.5700)$ & $(-2.5180)$ \\
\hline
\end{tabular}




\begin{tabular}{|c|c|c|c|c|c|c|}
\hline & $1999-2006$ & 51 & $\begin{array}{l}0.2036^{\star} \\
(1.4918)\end{array}$ & $\begin{array}{l}0.0640^{\star \star \star} \\
(2.5448)\end{array}$ & $\begin{array}{l}0.4069 * \\
(1.6368)\end{array}$ & $\begin{array}{l}-0.2385 \\
(-1.0210)\end{array}$ \\
\hline Delisting & $1986-2006$ & 20 & $\begin{array}{l}-0.4078^{\star \star \star} \\
(-3.4745)\end{array}$ & $\begin{array}{l}-0.0019 \\
(-0.2431)\end{array}$ & $\begin{array}{l}-0.6256^{\star \star \star} \\
(-4.2989)\end{array}$ & $\begin{array}{l}0.3447^{\star *} \\
(2.3789)\end{array}$ \\
\hline
\end{tabular}


Table 7: Changes in the components of the Dimson-Fowler-Rorke slope coefficients before and after option listing

This table reports the cross-sectional average of the changes in the leading and lag components of the DFR slope coefficients before and after option listing. For each event (listing or delisting), the univariate model:

$R_{i, t}=\alpha_{i}+\sum_{i=-K}^{K} \beta_{i, 2} R_{o s n, i+2}+\varepsilon_{i, t}$

and the bivariate model

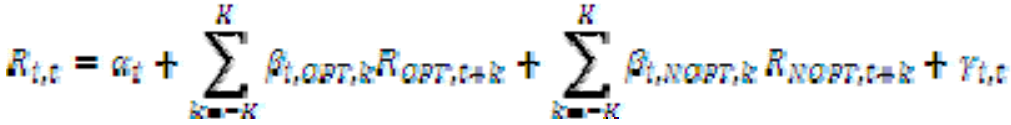

are estimated separately for each stock before and after each event, where $K=2$ for weekly returns and $K=5$ for daily returns. Thereafter, the Dimson-Fowler-Rorke (DFR) adjusted factor loadings are calculated as:

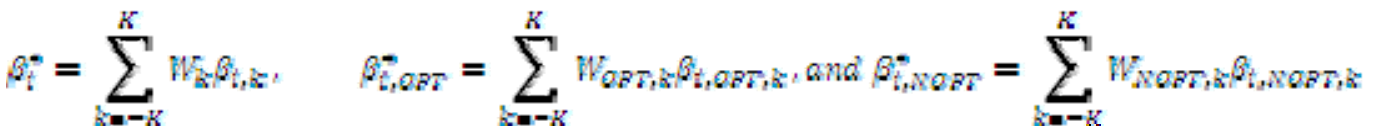

$\bar{\square}$ is the cross-sectional average of the change in the DFR adjusted slope coefficients for the univariate model. For the bivariate model, $\overline{\Delta G_{\triangle B S}}$, is the cross-sectional average of the change in the DFR adjusted factor loading on the portfolio of optioned stocks, and $\overline{\Delta \beta_{\text {NOPT }}}$, is the factor loading on the portfolio of non-optioned stocks. Panel A report results for the daily returns analysis, whilst Panel B shows results for the weekly return analysis.

\begin{tabular}{|c|c|c|c|}
\hline & Univariate & & ate \\
\hline & $\overline{\Delta Q}$ & $\overline{\Delta Q_{Q R T}}$ & $\overline{\Delta \beta_{\text {MORS }}}$ \\
\hline Panel A: Daily Re & & & \\
\hline t-5 & -0.0053 & $0.0547^{\star}$ & -0.0480 \\
\hline & $(-0.2613)$ & (1.4196) & $(-1.1167)$ \\
\hline $\mathrm{t}-4$ & 0.0048 & -0.0124 & -0.0246 \\
\hline & (0.2531) & $(-0.3333)$ & $(-0.5323)$ \\
\hline$t-3$ & $-0.0384^{\star \star}$ & $-0.0896^{\star *}$ & $0.0915^{\star \star}$ \\
\hline & $(-1.6870)$ & $(-2.3598)$ & $(2.0587)$ \\
\hline$t-2$ & 0.0153 & -0.0009 & 0.0237 \\
\hline & $(0.8221)$ & $(-0.0225)$ & $(0.4990)$ \\
\hline$t-1$ & $-0.0329^{\star}$ & -0.0188 & 0.0128 \\
\hline & $(-1.4122)$ & $(-0.4678)$ & $(0.2256)$ \\
\hline $\mathrm{T}$ & $0.1574^{\star \star \star}$ & $0.3476^{\star \star \star}$ & $-0.2412^{\star \star \star}$ \\
\hline & (3.1378) & (6.2601) & $(-3.2088)$ \\
\hline$t+1$ & -0.0095 & $-0.0754^{\star \star}$ & $0.0819 * *$ \\
\hline & $(-0.4660)$ & $(-1.8067)$ & $(1.7077)$ \\
\hline$t+2$ & $0.0498^{\star * \star}$ & $0.0805^{\star *}$ & -0.0384 \\
\hline
\end{tabular}




$\begin{array}{llll} & (2.6459) & (1.7847) & (-0.6585) \\ \mathrm{t}+3 & 0.0378^{\star \star} & 0.0218 & 0.0243 \\ & (1.7134) & (0.5539) & (0.5209) \\ \mathrm{t}+4 & & & \\ & -0.0361^{\star *} & 0.0007 & -0.0307 \\ & (-1.9436) & (0.0158) & (-0.5859) \\ & & & \\ & -0.0110 & -0.0592^{\star *} & 0.0573 \\ & (-0.5840) & (-1.6724) & (1.2896)\end{array}$

Table 7: Changes in the components of the Dimson-Fowler-Rorke slope coefficients before and after option listing

\begin{tabular}{|c|c|c|c|}
\hline & \multicolumn{2}{|l|}{ Univariate } & Bivariate \\
\hline & $\overline{\Delta Q}$ & $\overline{\Delta G_{Q R T}}$ & $\overline{\Delta G_{\text {XQRT }}}$ \\
\hline \multicolumn{4}{|c|}{ Panel B: Weekly Returns } \\
\hline \multirow[t]{2}{*}{$t-2$} & -0.0098 & 0.0774 & $-0.1050^{*}$ \\
\hline & $(-0.2836)$ & $(1.1385)$ & $(-1.4423)$ \\
\hline \multirow[t]{2}{*}{$t-1$} & 0.0068 & 0.0752 & -0.0487 \\
\hline & $(0.2163)$ & $(1.0703)$ & $(-0.6898)$ \\
\hline \multirow[t]{2}{*}{$\mathrm{T}$} & $0.1633^{\star * *}$ & $0.3338^{\star \star \star}$ & $-0.2102^{\star \star *}$ \\
\hline & $(2.8002)$ & $(3.8606)$ & $(-3.0056)$ \\
\hline \multirow[t]{2}{*}{$t+1$} & -0.0322 & -0.0583 & 0.0358 \\
\hline & $(-1.0190)$ & $(-0.8986)$ & (0.5578) \\
\hline \multirow[t]{2}{*}{$t+2$} & $-0.0814^{\star \star \star}$ & -0.0764 & 0.0187 \\
\hline & $(2.7876)$ & $(-1.2875)$ & $(0.2792)$ \\
\hline
\end{tabular}

${ }^{* \star *},{ }^{* *}$, and ${ }^{*}$ denote statistical significance (one-tail t-test) at the $1 \%, 5 \%$, and $10 \%$ level respectively 


\section{Table 8: Descriptive statistics of the volume measures}

The table presents descriptive statistics of daily options and stock trading volume measures 12 months after option listing. The sample includes stock option listings between 1991 and 2007 that have sufficient post-listing options and stock volume data. For each volume measure we report the cross-sectional distribution for periods of normal trading volume, high trading volume and the full sample period. We define a trading volume measure on a particular day as high if the volume measure belongs to the highest $30 \%$ volume bracket in a given quarter. For each firm in the sample, we first calculate the time series average over the 12 month period. The table shows the cross-sectional distribution of the time series averages.

$$
\text { N Mean Minimum Q1 } \quad \text { Median } \quad \text { Q3 } \quad \text { Maximum }
$$

Panel A: Turnover by Value (VA) measured in $\mathrm{f}^{\prime} 000 \mathrm{~s}$

$\begin{array}{cccccccc}\text { Normal } & 40 & 26.4 & 1.9 & 10.9 & 18.4 & 37.0 & 134.7 \\ \text { High } & 40 & 63.6 & 6.9 & 27.1 & 49.2 & 89.6 & 292.9 \\ \text { Overall } & 40 & 37.5 & 3.3 & 15.6 & 29.6 & 52.0 & 179.4 \\ \text { Turnover by Volume (VO) measured in ‘000s of shares traded } & & & & \\ \text { Normal } & 40 & 6,715.0 & 552.0 & 2,162.0 & 3,241.0 & 9,927.0 & 31,213.0 \\ \text { High } & 40 & 16,800.0 & 1,961.0 & 5,586.0 & 7,906.0 & 25,611.0 & 76,188.0 \\ \text { Overall } & 40 & 9,722.0 & 961.0 & 3,169.0 & 4,545.0 & 16,053.0 & 43,538.0\end{array}$

Panel C: Total Option Volume (VM) measured in number of contracts traded

$\begin{array}{cccc}\text { Normal } & 40 & 27.7 & 0.4 \\ \text { High } & 40 & 369.7 & 15.5 \\ \text { Overall } & 40 & 127.0 & 5.1\end{array}$

$\begin{array}{llll}2.3 & 11.2 & 34.2 & 277.6\end{array}$

$\begin{array}{llll}81.6 & 184.1 & 480.2 & 3,090.7\end{array}$

Overall

40

81.6

184.1

144.7

$1,111.5$

Panel D: Put Option Volume (PVM) measured in number of contracts traded

$\begin{array}{cccc}\text { Normal } & 40 & 8.4 & 0.0 \\ \text { High } & 40 & 181.2 & 10.4 \\ \text { Overall } & 40 & 55.7 & 2.9\end{array}$

0.6

19

$\begin{array}{ll}7.1 & 104.8\end{array}$

$\begin{array}{llll}35.7 & 113.6 & 200.7 & 1,470.6\end{array}$

Overall

40

2.9

Panel E: Call Option Volume (CVM) measured in number of contracts traded

$\begin{array}{cccccccc}\text { Normal } & 40 & 11.4 & 0.06 & 0.6 & 3.4 & 14.9 & 100.4 \\ \text { High } & 40 & 223.8 & 7.5 & 43.8 & 109.1 & 255.6 & 1,814.7 \\ \text { Overall } & 40 & 71.3 & 2.2 & 12.2 & 34.4 & 82.4 & 601.8\end{array}$


Table 9: Increase/Decrease in factor loadings on the optioned stock portfolio and non-optioned stock portfolio during periods of high trading volume relative to normal trading periods.

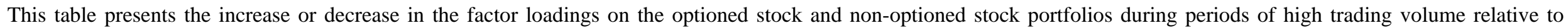

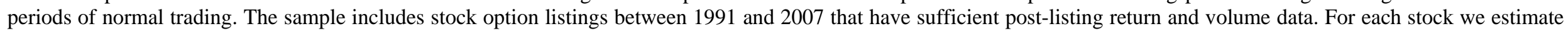
the models:

and

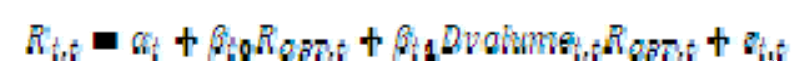

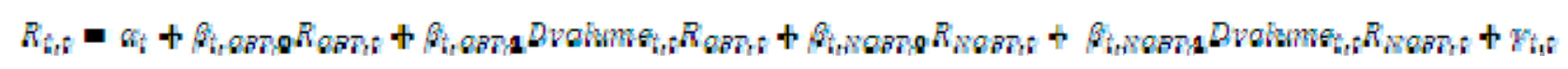

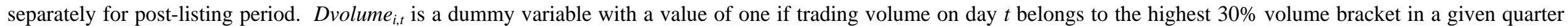

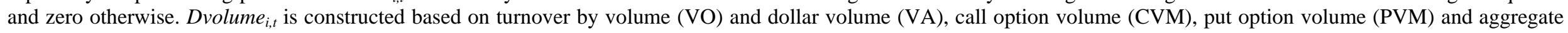
option volume (VM). The table shows the cross-sectional averages of the various parameter estimates and their associated t-values. The t-values (shown in parenthesis) are based on standard errors clustered by month to adjust for any possible dependencies across the sample. The column labelled CVM, presents the results of the analysis where Dvolume $e_{i, t}$

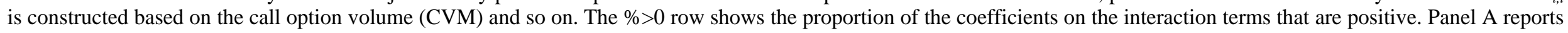

\begin{tabular}{|c|c|c|c|c|c|c|c|c|c|c|c|c|c|c|c|}
\hline & \multicolumn{5}{|c|}{ Panel A: Results for Eq.(8) } & \multicolumn{10}{|c|}{ Panel B: Results for Eq.(9) } \\
\hline & CVM & PVM & VM & vo & VA & CVM & PVM & VM & vo & VA & CVM & PVM & VM & vo & VA \\
\hline $\mathrm{R}_{\mathrm{OPT}}$ & $\begin{array}{l}1.0454^{\star \star \star} \\
(11.8520)\end{array}$ & $\begin{array}{l}1.0803^{\star \star \star} \\
(10.8426)\end{array}$ & $\begin{array}{l}1.0634^{\star \star \star} \\
(11.5296)\end{array}$ & $\begin{array}{l}1.0069 \star \star \star \\
(13.2815)\end{array}$ & $\begin{array}{l}1.0249 * \star \star \\
(12.5053)\end{array}$ & $\begin{array}{l}0.5681^{\star \star \star} \\
(11.0670)\end{array}$ & $\begin{array}{l}0.5930 * * \star \\
(10.0666)\end{array}$ & $\begin{array}{l}0.5747^{\star \star \star} \\
(10.9581)\end{array}$ & $\begin{array}{l}0.6590^{\star \star \star} \\
(13.5514)\end{array}$ & $\begin{array}{l}0.6748^{\star \star \star} \\
(13.3162)\end{array}$ & & & & & \\
\hline $\mathrm{R}_{\text {NOPT }}$ & & & & & & & & & & & $\begin{array}{c}0.6573^{\star \star \star} \\
(6.3996)\end{array}$ & $\begin{array}{c}0.6712^{\star \star \star} \\
(5.4846)\end{array}$ & $\begin{array}{c}0.6768^{\star \star \star} \\
(5.4967)\end{array}$ & $\begin{array}{c}0.4979 * * * \\
(5.9011)\end{array}$ & $\begin{array}{c}0.4938^{* * *} \\
(6.0436)\end{array}$ \\
\hline Dvolume x $\mathrm{R}_{\mathrm{NOPT}}$ & & & & & & & & & & & $\begin{array}{c}-0.0023 \\
(-0.0216)\end{array}$ & $\begin{array}{c}-0.0137 \\
(-0.1055)\end{array}$ & $\begin{array}{c}-0.0375 \\
(-0.3793)\end{array}$ & $\begin{array}{l}0.2548^{\star \star} \\
(2.3970)\end{array}$ & $\begin{array}{l}0.3100^{\star *} \\
(2.4578)\end{array}$ \\
\hline$\%>0$ & $\begin{array}{l}0.700^{\star \star *} \\
(2.5298)\end{array}$ & $\begin{array}{l}0.725^{\star \star \star} \\
(2.8460)\end{array}$ & $\begin{array}{l}0.725^{\star \star \star} \\
(2.8460) \\
\end{array}$ & $\begin{array}{l}0.750 * \star * \\
(3.1623)\end{array}$ & $\begin{array}{l}0.775^{\star \star \star} \\
(3.4785)\end{array}$ & $\begin{array}{c}0.625^{\star} \\
(1.5811)\end{array}$ & $\begin{array}{c}0.575 \\
(0.9487) \\
\end{array}$ & $\begin{array}{c}0.625^{\star} \\
(1.5811)\end{array}$ & $\begin{array}{c}0.450 \\
(-0.6325) \\
\end{array}$ & $\begin{array}{c}0.375^{\star} \\
(-1.5811) \\
\end{array}$ & $\begin{array}{c}0.425 \\
(-0.9487) \\
\end{array}$ & $\begin{array}{c}0.475 \\
(-0.3162) \\
\end{array}$ & $\begin{array}{c}0.475 \\
(-0.3162) \\
\end{array}$ & $\begin{array}{l}0.650^{\star *} \\
(1.8974)\end{array}$ & $\begin{array}{c}0.675^{\star *} \\
(2.2136)\end{array}$ \\
\hline
\end{tabular}
results for Eq. (8), whilst Panel B shows results for Eq. (9). 
${ }^{* * *},{ }^{* *}$, and * denote statistical significance (one-tail t-test) at the $1 \%, 5 \%$, and $10 \%$ level respectively 
Fig. 1: Volatility of optioned and non-optioned portfolio returns and the correlation between them. This figure shows the standard deviations of the returns of the portfolio of optioned stocks, $\sigma(\mathrm{OPT})$, and the nonoptioned portfolio, $\sigma(\mathrm{NOPT})$, plotted against the left axis and the correlation between the two portfolios, corr(OPT, NOPT), plotted against the right axis, over time. Panel A shows results for daily returns, Panel B shows weekly returns whilst Panel C shows monthly returns.

Panel A: Daily returns

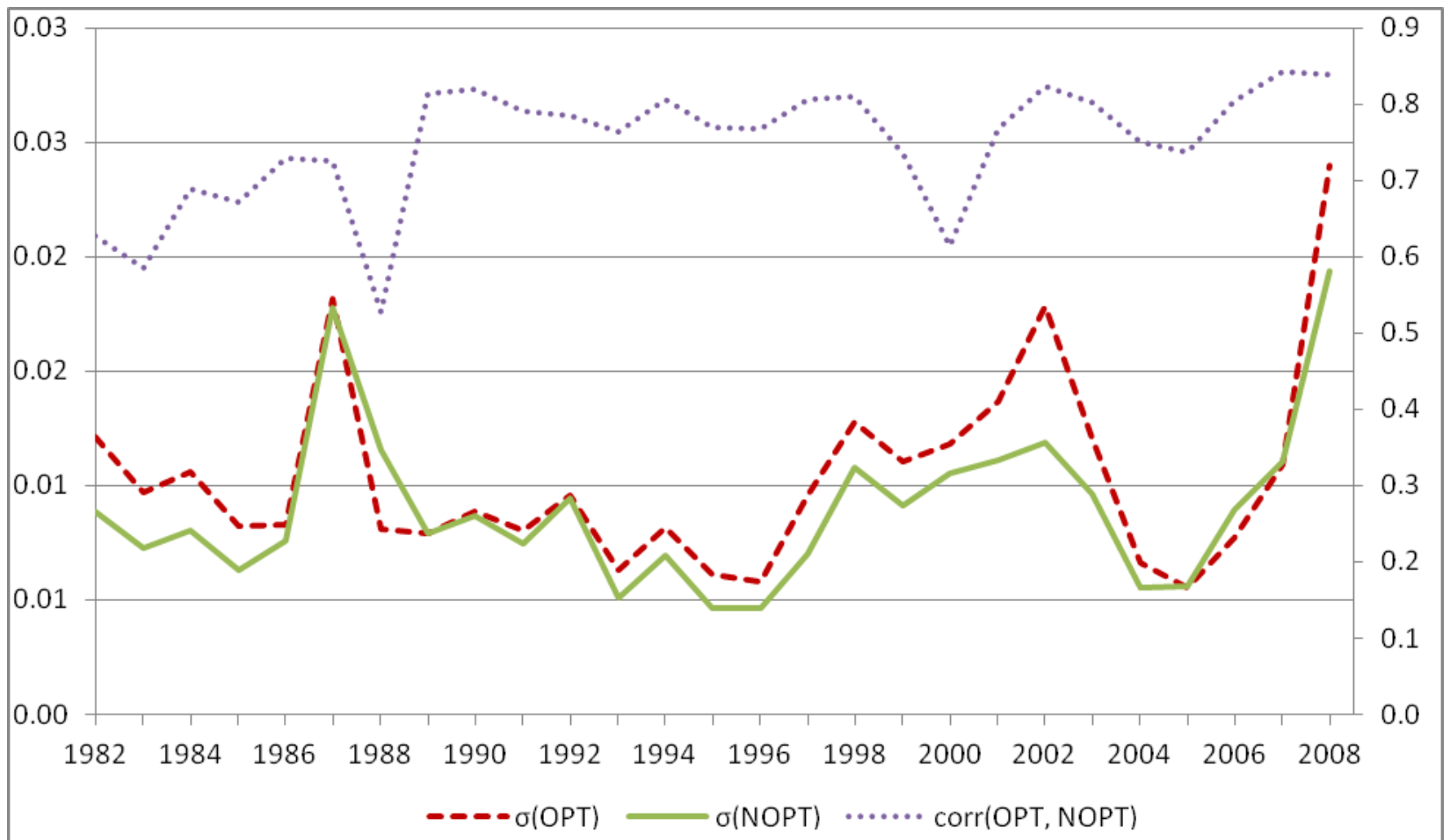

Panel B: Weekly returns

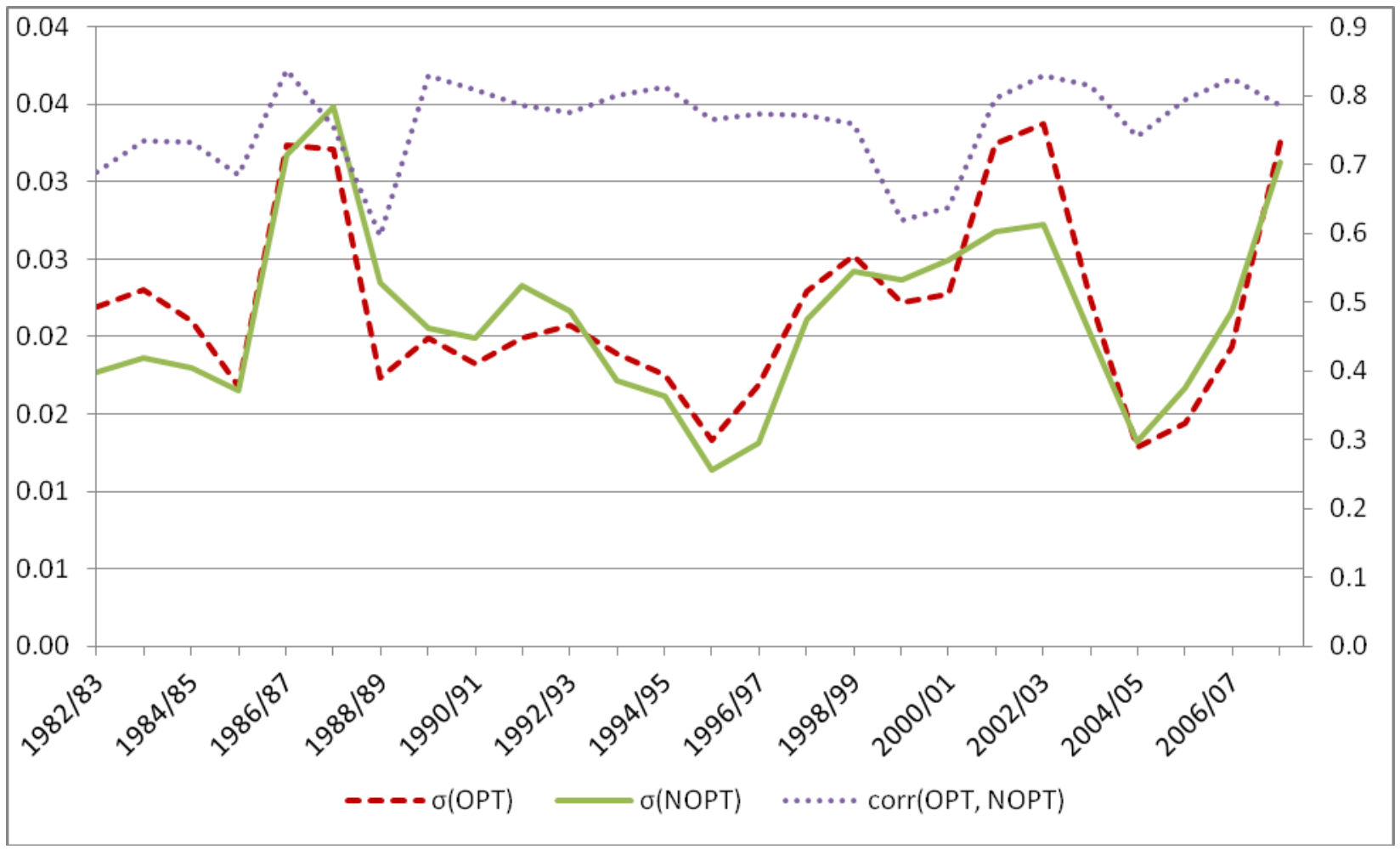


Panel C: Monthly returns

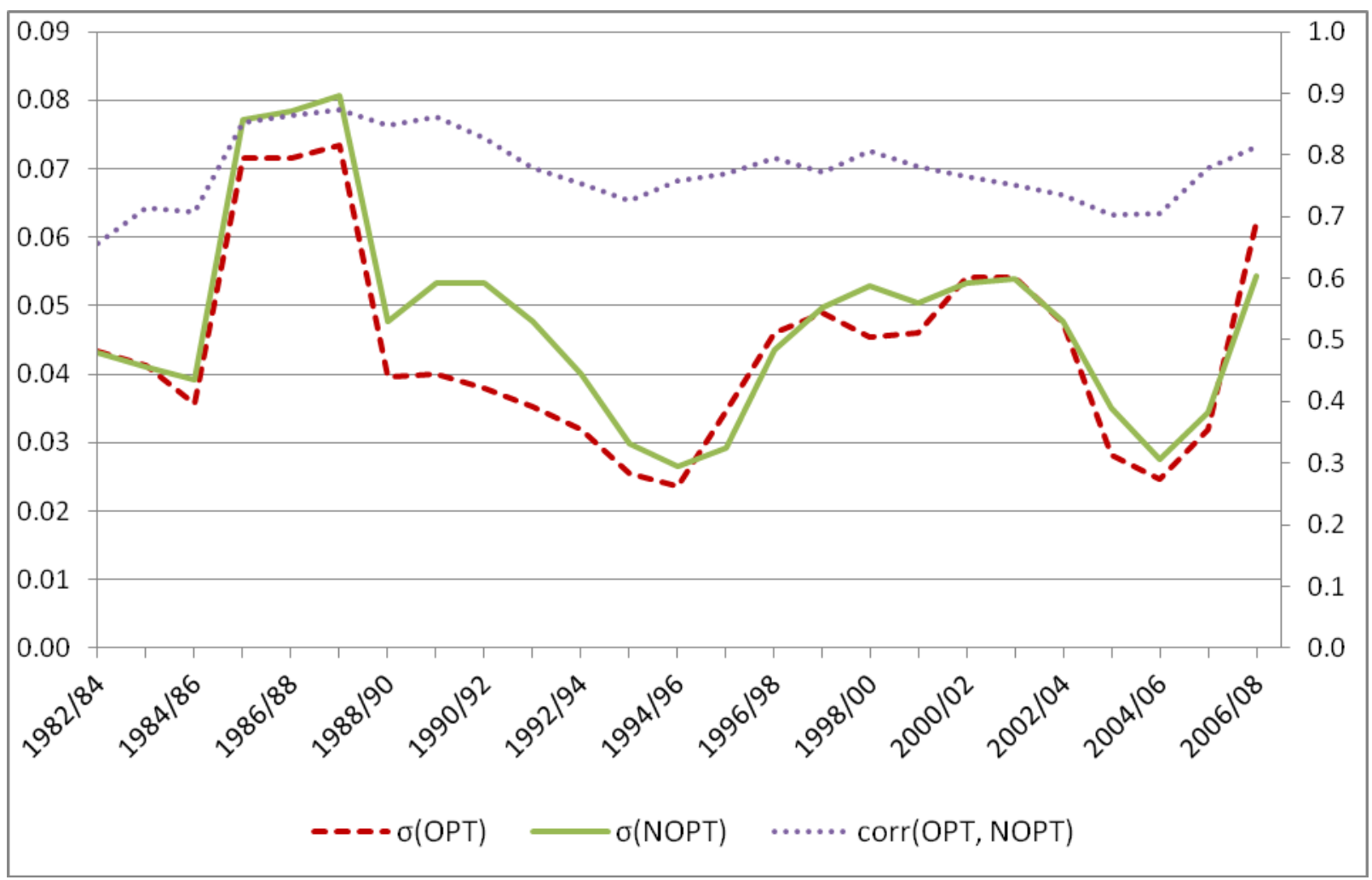

